\title{
Dual-Color Double Stars in Ruby, SAPPHIRE, AND QUARTZ: CAUSE AND Historical ACCOUNT
}

Karl Schmetzer, Martin P. Steinbach, H. Albert Gilg, and Andrea R. Blake

A largely overlooked form of asterism consisting of dual-color double stars is found in natural sapphire, in diffusion-treated and non-diffusion-treated synthetic rubies and sapphires, and in natural quartz. To characterize and explain this phenomenon, examples of these materials were examined. In transparent or translucent samples, an optical pattern of a white six-rayed star and a bodycolored (e.g., red, orange, yellow, green, blue) six-rayed star was frequently observed. Grinding and repolishing experiments showed that the asterism of part of the synthetic samples was produced or enhanced by diffusion treatment. The mechanism responsible for the formation of the dual-color double stars is discussed. To produce the pattern, acicular inclusions must either be present in relatively thin layers confined to the dome and the base of diffusion-treated ruby or sapphire cabochons, or be distributed throughout the complete corundum (natural or synthetic) or quartz samples. The white star is caused by interaction of light with the upper layer of the cabochon's dome. The bodycolored star, in contrast, is generated by light that enters the cabochon, is reflected and scattered at the base layer of the cabochon, and then travels a second time back through the body of the sample. As further prerequisites for observation of the phenomenon, the gemstones must be transparent or translucent, with polished base and dome.

A historical summary of the manufacture and improvement of synthetic asteriated corundum by diffusion treatment offers additional insight into dual-color double-star stones. According to firsthand accounts and patent documents, diffusion has been used to produce or enhance asterism in synthetic and natural corundum since the 1950s. The treated material has been released commercially since at least the 1970s, and it is still produced and found on the international market.

A sterism in corundum and quartz is observed in various forms. Single six-rayed asterism is the most common form, found in natural ruby and sapphire from different sources around the world. This optical phenomenon is due to the presence of three series of acicular inclusions, in corundum mostly identified as rutile or hematite-ilmenite needles (Moon and Phillips, 1984). If both types of inclusion are present, twelve-rayed asterism is seen (Hughes, 1997; Schmetzer and Glas, 2001). In such samples, two six-rayed concentric stars consisting of three light bands each are rotated such that the twelve rays are evenly spaced and $30^{\circ}$ apart (and alternate between the two acicular inclusion types).

See end of article for About the Authors and Acknowledgments.

Gems \& Gemology, Vol. 51, No. 2, pp. 112-143,

http://dx.doi.org/10.5741/GEMS.51.2.112.

(C) 2015 Gemological Institute of America
Asteriated natural sapphires and rubies with two slightly displaced six-rayed stars of identical white color have been mentioned on different occasions. This optical phenomenon results from lamellar twinning, with three series of rutile needles in each individual part of the twin (Koivula et al., 1993; McClure, 1998; Kondo, 2007).

Additionally, a natural star sapphire with two stars of different coloration was described by Koivula and Tannous (2001). The two stars were observed singly but on opposite sides of the double cabochoni.e., the color of the star visible depended upon whether the stone was viewed from the "top" dome or the "bottom" dome. One star was an "ordinary" white star of the type commonly seen in sapphires and rubies, caused by reflection from inclusions near the surface toward the viewer. The other was a yellow-brown star, caused by reflection from inclusions 
farther from the surface and thereby showing superimposition of the bodycolor of the host sapphire.

Phenomenal quartz has been known from various localities for more than a century, and asteriated material is seen occasionally in the trade, with most samples originating from Brazil or Madagascar (Cassedanne and Roditi, 1991; Pezzotta, 2001). The literature further demonstrates that asterism and related phenomena in quartz constitute a relatively complex topic and may take a plurality of forms. Most common are asteriated stones presenting sixrayed stars, with three groups of needle-like inclusions oriented in a plane perpendicular to the c-axis. Rarely, twelve-rayed stars are observed, which show six groups of needles (two sets of three) in the same plane. Even multi-star quartz samples revealing numerous stars on the surface of cabochons or complete spheres have been described in detail from a locality near Galle in Sri Lanka (Schmetzer and Glas, 2003). Rose quartz spheres also may show isolated light spots in addition to the typical six-rayed asterism (Schmetzer and Krzemnicki, 2006).

With respect to identification of the needles producing the phenomena, asterism in colorless quartz and rose quartz has frequently been associated with the presence of a network of oriented rutile needles (see, e.g., Eppler, 1958; Fryer et al., 1981, 1982b, 1985;

\section{In Brief}

- Corundum (natural and synthetic) and quartz may exhibit asterism in the form of dual-color double stars.

- Reflection and scattering of light by acicular inclusions near the dome of cabochons create a white star, while such reflection and scattering of light by inclusions near the base create another star with the bodycolor of the host.

- Diffusion processes may contribute to the phenomenon and have been used to create or improve asterism in ruby and sapphire since the 1950 s.

Kiefert, 2003). Rutile needles are found in quartz in a multiplicity of crystallographic orientations, as established by von Vultée $(1955,1956)$. By use of five of these established orientations for rutile needles in quartz, a model was developed to explain all observed multi-star networks in quartz from Sri Lanka (Schmetzer and Glas, 2003). A sagenitic network of acicular rutile crystals has also been mentioned recently as causing the asterism seen in quartz samples from Myanmar (Schmetzer and Steinbach, 2014).
In addition, examinations of six-rayed star quartz from Niriella, Sri Lanka, showed the presence of three series of oriented sillimanite needles (Woensdregt et al., 1980). Oriented needle-like inclusions of ilmenite, on the other hand, were responsible for the six light bands in quartz from the state of Texas (Zolensky et al., 1988). In a yellow-green quartz from Tamil Nadu, India, showing a combination of asterism and chatoyancy, several series of unidentified fine to coarse needles were described (Choudhary and Vyas, 2009). These publications show that although rutile needles seem to be a well-established cause for asterism in some quartz varieties, other acicular inclusions should not be neglected.

To summarize, table 1 offers a short overview of the different star phenomena.

\section{PRODUCTION OF ASTERIATED SYNTHETIC RUBY AND SAPPHIRE}

In synthetic ruby and sapphire, asterism is produced in a two-step process:

1. Growth of a non-asteriated crystal that contains distinct amounts of titanium in the corundum lattice

2. Heat treatment of the homogeneous titaniumbearing sample to form needle-like precipitates of a titanium-bearing phase

Two variants are known for the first step of this process. In one variant, titanium oxide is added to the aluminum oxide powder used for the production of synthetic ruby and sapphire boules by the Verneuil method (Burdick and Glenn, 1949; Burdick and Jones, 1954a) or by the Czochralski technique (Keig et al., 1972). In another variant, titanium is diffused into whole and half boules as well as pre-cut cabochons of synthetic Verneuil-grown corundum (Eversole and Burdick, 1954c; see also Carr and Nisevich, 1975a, 1976a, 1977).

After either variant of the first production step, heat treatment is performed for the formation of needle-like precipitates in the corundum matrix. This step exsolves three differently oriented series of needles, composed either of rutile or of another titanium-bearing phase. Reflection and scattering of light from these needles are then responsible for the three intersecting light bands of asteriated rubies and sapphires. The exsolution step is necessary regardless of which variant of the first production step is employed. 
TABLE 1. Overview of various star phenomena.

\begin{tabular}{|c|c|c|}
\hline & Ruby and sapphire & Quartz and rose quartz \\
\hline Single six-rayed star & $\begin{array}{l}\text { Three series of needles in } \\
\text { planes parallel to the basal } \\
\text { face }\end{array}$ & $\begin{array}{l}\text { Three series of needles in } \\
\text { planes parallel to the basal } \\
\text { face }\end{array}$ \\
\hline Single twelve-rayed star & $\begin{array}{l}\text { Six series of needles (two } \\
\text { sets of three) in planes } \\
\text { parallel to the basal face }\end{array}$ & $\begin{array}{l}\text { Six series of needles (two } \\
\text { sets of three) in planes } \\
\text { parallel to the basal face }\end{array}$ \\
\hline $\begin{array}{l}\text { Single-color double stars } \\
\text { consisting of two } \\
\text { displaced stars with } \\
\text { identical color }\end{array}$ & $\begin{array}{l}\text { Twinned individual, each } \\
\text { part of the twin with a } \\
\text { single six-rayed star }\end{array}$ & \\
\hline $\begin{array}{l}\text { Multiple stars with } \\
\text { identical color }{ }^{\mathrm{a}} \text { (or } \\
\text { additional light spots) }\end{array}$ & & $\begin{array}{l}\text { Several series of needles } \\
\text { parallel and inclined to } \\
\text { the basal face (or } \\
\text { additional flat inclusions) }\end{array}$ \\
\hline $\begin{array}{l}\text { Dual-color double stars } \\
\text { with a white star and a } \\
\text { bodycolored second star }\end{array}$ & $\begin{array}{l}\text { To be described in this } \\
\text { paper }\end{array}$ & $\begin{array}{l}\text { To be described in this } \\
\text { paper }\end{array}$ \\
\hline
\end{tabular}

${ }^{a}$ Also observed in garnets and spinels due to the cubic symmetry of the host (see, e.g., Schmetzer et al., 2002)

Numerous papers have dealt with the examination and identification of the needle-like precipitates formed in Ti-doped corundum after annealing at temperatures in the range of $1500^{\circ}$ to $1100^{\circ} \mathrm{C}$ (see references below and patent documents in table A-1). The different phases present as acicular inclusions have been characterized in the transmission electron microscope using electron diffraction and/or other microanalytical techniques. It has often been noted that twinned rutile needles are formed, but the exsolution of rhombic or monoclinic $\mathrm{TiO}_{2}$ phases and even the formation of $\mathrm{Al}_{2} \mathrm{TiO}_{5}$ have been reported as well (Phillips et al., 1980; Langensiepen et al., 1983; Moon and Phillips, 1991; Xiao et al., 1997; Viti and Ferrari, 2006; He et al., 2011). For simplicity, we shall only mention "rutile" needles or precipitates, aware of the fact that other Ti-bearing phases might also be present.

Patents related to the different variants of production mentioned above were assigned to the Linde Air Products Company (New York) and later to Union Carbide and Carbon Corporation or to Union Carbide Corporation (of which Linde had become a division). Linde started manufacturing synthetic ruby and sapphire in the United States in the 1940s, when America was cut off from European supply of synthetic corundum ("U.S. develops synthetic sapphire industry," 1943; Alexander, 1946; Seemann, 1949; Pough, 1966). The method to produce asteriated corundum was discovered by J.N. Burdick and his colleagues at Linde in 1947 (see "The story of Linde stars," n.d.), and the first samples were available for gemological examination in the same year (Holmes, 1947). Linde's only competitor for the international market in the early decades of production was Wiede's Carbidwerk in Freyung, Germany (Breebaart, 1957; Ep- 


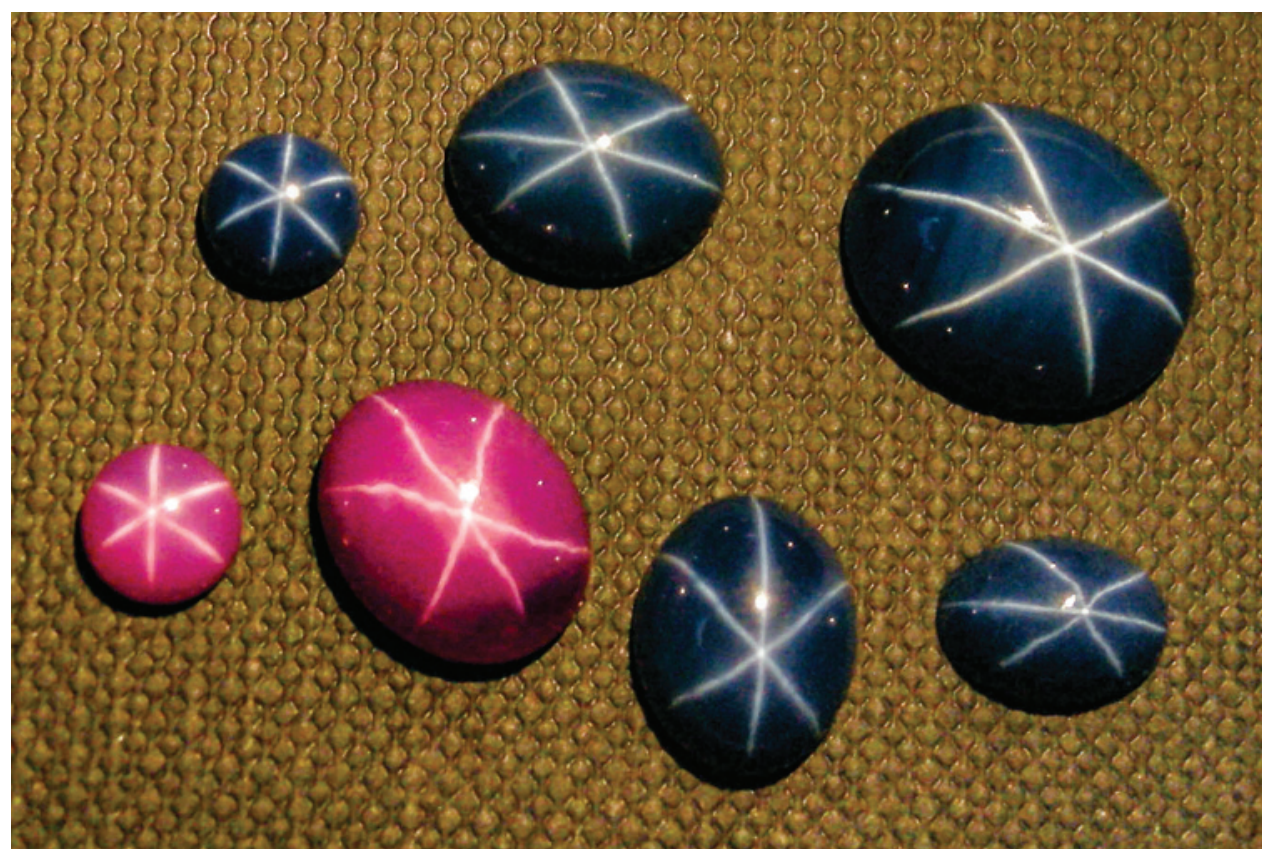

Figure 1. Synthetic star rubies and sapphires were manufactured by the Linde Air Products Company beginning in the late 1940s. The first commercially produced type of asteriated stones was opaque with a white, six-rayed star. The large ruby cabochon measures 9.9 $\times 8.0 \mathrm{~mm}$ and weighs 3.39 ct. Photo by K. Schmetzer; samples courtesy of C. Cavey.

pler, 1957/1958). This company has been growing synthetic corundum since 1913. The existence of a competing manufacturer was possible because the basic patent (Burdick and Glenn, 1949) was granted only in the United States (see box A), and Wiede's developed and patented a slightly different process in Germany (Ancot and Eppler, 1957 a,b).

The asteriated synthetic rubies and sapphires produced by Linde (figure 1) were distributed and sold under various trade names, including the widely used "Linde stars." In the 1960s, asteriated corundum was commercially available in four different colors (white, red, blue, and black), and limited quantities of asteriated sapphires in other colors (green, yellow, and pink) were also produced (Meyer-Browne, 1962; Thurm, 1962; Taylor, 1964; Pough, 1966). Due to the concentration of needle-like precipitates primarily in a thin layer close to the surface of the Verneuil boules, the first stones manufactured showed higher transparency and somewhat incomplete stars compared to the material released from 1952 onward (Holmes, 1947; Liddicoat, 1963; Crowningshield, 1965). Production of synthetic star rubies and sapphires in the United States ceased in 1974 (Nassau, 1979). Conversely, production of non-asteriated, titanium-bearing sapphires continued. At Union Carbide, these titanium-bearing synthetics were grown using the Czochralski method and were primarily used as laser crystals, although such material with pink coloration has occasionally been faceted for gem use (Johnson et al., 1995).
It has been mentioned in the literature that synthetic star stones produced by diffusion have a higher transparency than normal star corundum but have not been marketed on a wide scale (Elwell, 1979). It was also noted that the diffusion process has not normally been used for producing synthetic stars (Nassau, 1980). However, no information as to the source of these statements is provided in the cited texts.

Asterism in natural corundum can be created or improved by the same diffusion process with subsequent heat treatment as described above. The related patent applications were assigned to Union Carbide Corporation (Carr and Nisevich, 1975a) or later to Astrid Corporation (Carr and Nisevich, 1976a, 1977).

\section{RECOGNITION OF DUAL-COLOR DOUBLE-STAR PHENOMENA IN CORUNDUM AND QUARTZ}

Corundum and quartz samples showing a type of star phenomenon not accounted for among the more widely recognized forms of asterism described earlier and consisting of two differently colored six-rayed stars have occasionally been noted or depicted as well. For example, a double-star pattern was pictured by Arem (1987) for some synthetic "Heller Hope" star rubies and sapphires (a trade name used for Linde synthetics). The accompanying caption does not explicitly refer to these dual-color double stars, and in the text no comment related to this phenomenon is given. The material portrayed was a lot of mixedcolor asteriated rubies and sapphires from the trade, 


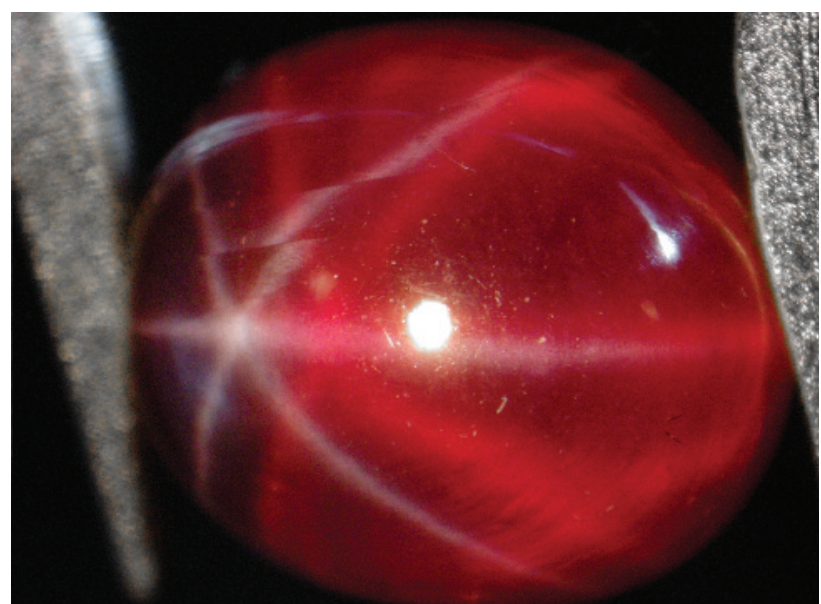

Figure 2. This synthetic star ruby was described by Schmetzer and Hainschwang (2012); the sample shows a six-rayed white star, reflected from the surface of the cabochon, and a six-rayed orange-red star. The sample measures $10.3 \times 8.7 \mathrm{~mm}$ and weighs 5.98 ct. Photo by K. Schmetzer.

without any additional specification (J.E. Arem, pers. comm., 2013). A similar photo showing differently colored sapphires with dual-color double stars was also published without further comment by Gübelin and Koivula (2008).

Another instance of a double star in a synthetic ruby was recently described by Schmetzer and Hainschwang (2012). When examined in reflected light, the ruby cabochon showed the ordinary whitish six-rayed star of corundum and an orange-red star that seemed to emanate from the back of the sample (figure 2). This transparent cabochon consisted of a Verneuil-grown synthetic corundum core with tiny needle-like precipitates in the upper layer (in the curved dome) as well as within the slightly curved base of the stone. It was concluded that the formation of the orange-red star was caused by a complex interaction of the light reflected and scattered by needles (most likely rutile needles) in one or both surface layers and absorption of light reflected from the base of the cabochon, traveling twice through the body of the stone.

An analogous double-star pattern consisting of two differently colored stars (white and pink) was observed in reflected light in a rose quartz sphere (Killingback, 2006, 2011). It was assumed that the light forming the pinkish star was "reflected from the rear surface of the sphere and formed into the star as it comes up through the ball, to be refracted at the top surface on leaving" the rose quartz sphere (Killingback, 2006).

Subsequent to the 2012 publication of the Schmetzer and Hainschwang paper, one of the authors (KS) discussed the mode of formation of the double-star pattern in the synthetic ruby with several colleagues. Although asterism is commonly observed in gem materials in reflected light, designated as epiasterism, transparent gemstones such as quartz or rose quartz also show asterism in transmitted light, termed diasterism (Schmetzer and Glas, 2003; Killingback, 2009). Taking these facts into consideration, it was argued that the phenomenon is probably a "simple" reflection of an ordinary white star (light bands produced by forward scattering) at the base of the cabochon, without further interaction of light with needle-like inclusions confined to that base and without further interaction with needles in the upper surface layer.

Thus, the opportunity to examine several additional samples of synthetic corundum purchased recently by one of the authors in Bangkok, which showed light bands forming a dual-color double star in reflected light (figure 3), was valuable. Furthermore, several lots of "Linde" synthetics loaned from various collections and samples bought in the trade, mainly in the United States in 2013, were examined and compared with the material obtained in the Bangkok trade. Synthetics produced by Wiede's Carbidwerk and Hrand Djevahirdjian SA were likewise made available for study. Finally, a similar-appearing double-star pattern was examined in a natural sapphire, in rose quartz from Brazil, and in brownish pink quartz from India. The focus in examining all of these samples was to elucidate the almost completely overlooked optical phenomenon of dual-color double stars observed in reflected light.

Figure 3. This pink synthetic sapphire showing a white six-rayed star and a pink star was purchased by one of the authors in Bangkok in 2010. The cabochon measures $14.4 \times 11.2 \mathrm{~mm}$ and weighs $12.37 \mathrm{ct}$. Photo courtesy of M.P. Steinbach.

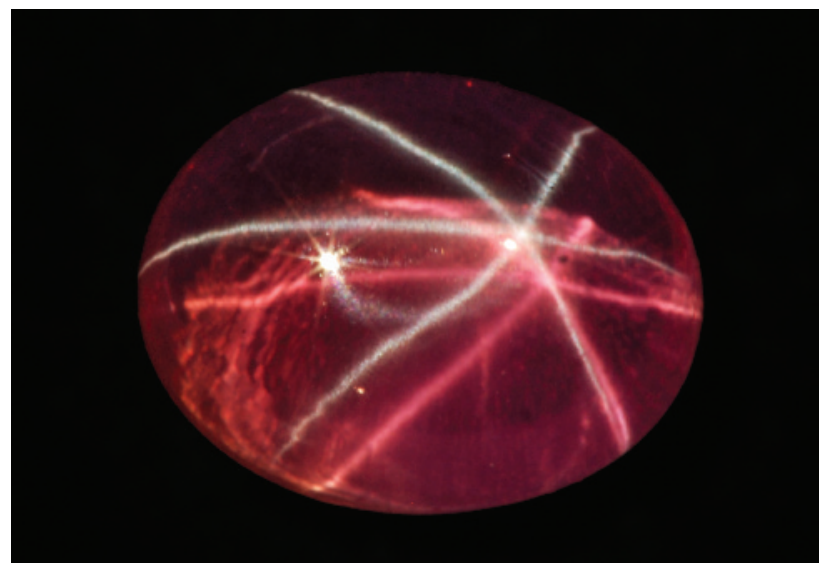




\section{Box A: TeChnical Information in Patent Documents}

Various processes to create or enhance asterism in corundum are described in patent documents that were filed by Linde or by the Linde division of Union Carbide, before the production and related patents were transferred to Astrid Corporation, a company based in Hong Kong (table A-1). The first patent application was filed in August 1947 (published as U.S. patent 2,488,507 in November 1949). In principle, and as already summarized in the text, the production of asteriated corundum is based on a two-step process comprising (1) the growth of titaniumbearing corundum crystals, and (2) the formation of rutile precipitates by low-temperature annealing between $1500^{\circ}$ and $1100^{\circ} \mathrm{C}$. These precipitates are responsible for the reflection and scattering of incident light and the formation of three intersecting light bands of a six-rayed star. According to the patent documents available, the two steps described are performed under various conditions. However, from interviews with people involved in the production (see box B), it appears that additional "secret" steps or specific details not disclosed in patents may exist to optimize the processes for obtaining asterism. The first synthetic asteriated rubies and sapphires were grown by the Verneuil technique, with the addition of a titaniumbearing compound as a component of the nutrient powder (Burdick and Glenn, 1949). Without further dopants, colorless star sapphires are obtained; with the addition of chromium oxide or iron oxide, respectively, rubies or blue sapphires can be produced.

The disadvantage of this basic process is that the resultant needle-like precipitates are confined to the skin of the Verneuil boules, thus restricting the size and number of the cabochons that may be cut. Cabochons cut from the interior of the boules may not exhibit asterism, and blue synthetic sapphires may also show colorless zones in the growth sectors without titanium (figure A1). Furthermore, cabochons cut with the titanium-bear-

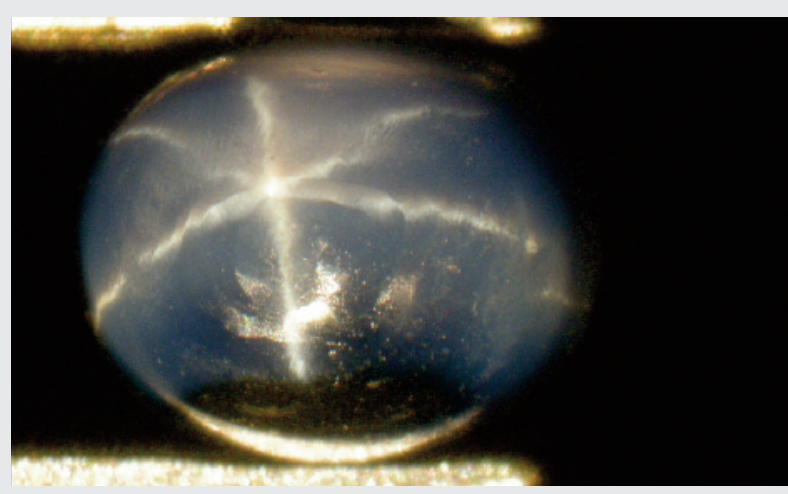

Figure A-1. Blue synthetic sapphire with a large colorless zone, which probably represents the core of the original boule; the star is restricted to the blue zones of the cabochon. The sample, from an unknown producer, measures $5.8 \times 4.8 \mathrm{~mm}$ and weighs $1.01 \mathrm{ct}$. Photo by K. Schmetzer.
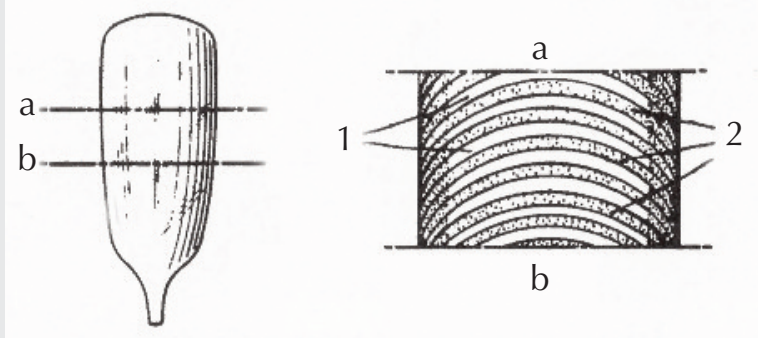

b

Figure A-2. Left: A boule of synthetic Verneuil-grown sapphire produced under fluctuating temperature conditions. Right: An enlarged section through the boule between lines $a$ and $b$ showing the distribution of titanium in various growth zones. 1 indicates layers containing titaniumbearing precipitates only at the rim; 2 represents layers containing titanium-bearing precipitates in all zones, from the center to the rim. After German patent DE 897 844. Inventors: J.N. Burdick and R.A. Jones (1954b); applicant: Union Carbide and Carbon Corporation.

ing skin in the center may not show asterism on the sides toward the base (Burdick and Jones, 1954a).

To overcome these disadvantages and to grow rubies and sapphires with more complete stars, and without colorless zones in blue sapphires, it was necessary to have a more homogeneous distribution of titanium in the crystals. The more homogeneous distribution was accomplished by growing the Verneuil boules under fluctuating thermal conditions. In practice, this fluctuation was achieved by alternately increasing and decreasing the rate of oxygen fed to the oxygen-hydrogen flame of the Verneuil burner. It is described in the Burdick and Jones (1954a) U.S. patent that the synthetic sapphire and ruby boules grown under such conditions show-in the direction of crystal growth-layers with high titanium contents in all zones, alternating with layers where titanium contents are restricted to the rim of the boule (figure A-2).

Larger crystals with an even more homogeneous titanium distribution are grown by the Czochralski technique (Keig et al., 1972, 1973a). Crystals produced by this method show a uniform distribution of both color and titanium-bearing precipitates. Asteriated cabochons can be cut from any section of the synthetic crystals without size or shape restriction. In practice, ruby or sapphire crystals are pulled vertically by means of a seed crystal (figure A3), which is dipped into an aluminum oxide melt doped with titanium oxide and further oxides of color-causing transition elements (e.g., chromium and iron).

An example of a large asteriated ruby that almost certainly was grown by Union Carbide using the Czochralski method, measuring $5 \mathrm{~cm}$ in diameter, was shown at a special exhibition at the Smithsonian Institution's National Museum of Natural History in the summer of 1973 (J.E. 


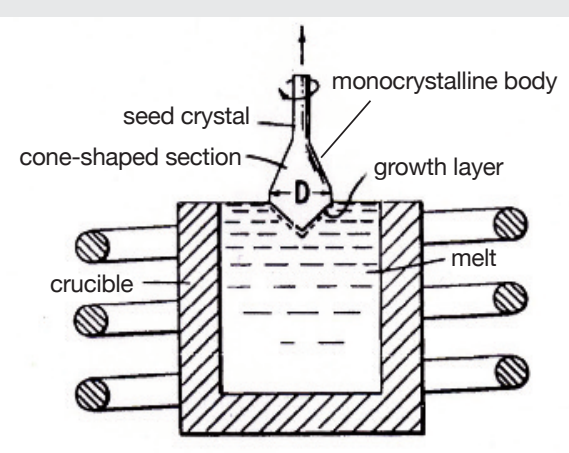

Figure A-3. Growth of a large sapphire crystal from the melt by the Czochralski technique. D represents the diameter of the growing crystal. After German published patent application DE 2208 150A. Inventors: G.A. Keig et al. (1973c); applicant: Union Carbide Corporation.

Arem, pers. comm., 2014; see figure A-4). However, this material was not available commercially, and further details of the production methods, especially for obtaining asterism, are unknown.

As an alternative to the methods described by Burdick and Jones (1954a) and Keig et al. (1972, 1973a), in which a titanium-bearing compound is added to the

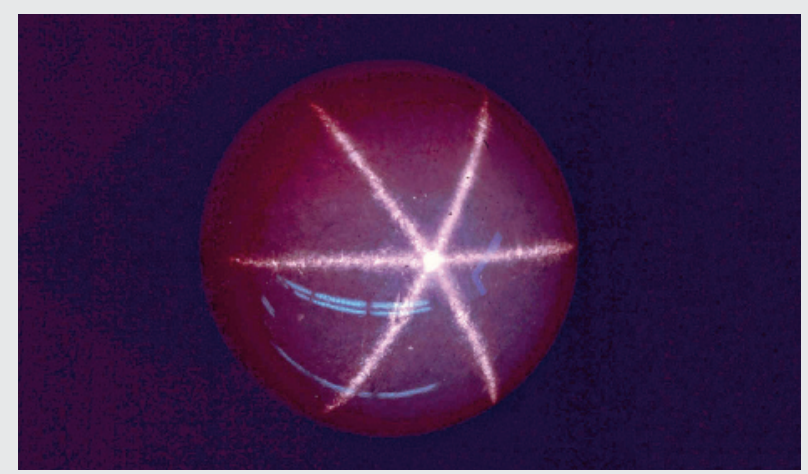

Figure A-4. This large sphere of asteriated synthetic ruby, about $5 \mathrm{~cm}$ in diameter, was exhibited at the Smithsonian Institution's National Museum of Natural History in the summer of 1973. It is an example of the large ruby and sapphire crystals manufactured at Union Carbide in the early 1970s, though details of its production are unknown. Photo courtesy of J.E. Arem.

powder used for crystal growth by the Verneuil or Czochralski technique, titanium can be induced into the corundum lattice by diffusion treatment of the alreadygrown, final crystal. This technique can also be applied to cabochon-cut materials. For the diffusion of titanium into the corundum, titanium oxide or a mixture of titanium oxide and aluminum oxide is placed in contact with a crystal, a boule, or a cabochon and annealed at temperatures in the range of $1950^{\circ}$ to $1700^{\circ} \mathrm{C}$ (Eversole and Burdick, 1954c).

As one example, the Eversole and Burdick (1954c)

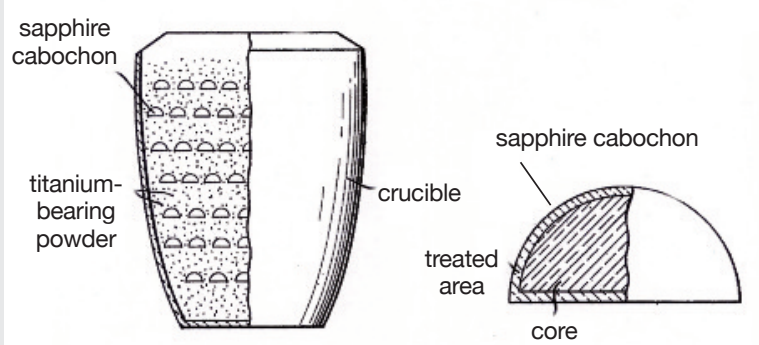

Figure A-5. Left: Diffusion treatment of sapphires in titanium-bearing powder. Right: A treated cabochon with a diffusion layer. After German published patent application DE 2262 104A. Inventors: R.R. Carr and S.D. Nisevich (1973c); applicant: Astrid Corporation.

patent describes spraying a slurry containing titanium oxide onto the surface of sapphire or ruby cabochons. To develop asterism, the cabochons are then annealed in a furnace at temperatures between $1875^{\circ}$ and $1800^{\circ} \mathrm{C}$. Another example involves embedding rubies or sapphires of various colors in a mixture of titanium oxide and aluminum oxide powder and then heating in crucibles at $1800^{\circ} \mathrm{C}$ for a period of 24 to 30 hours. Asterism is subsequently formed by the precipitation of titanium-bearing needles by low-temperature annealing as described above. The diffusion of titanium is restricted to a thin layer at the surface of the treated corundum boules or cabochons. This layer, however, is sufficient to produce the desired six-rayed asterism. It is worth noting that, although not worked out in detail,

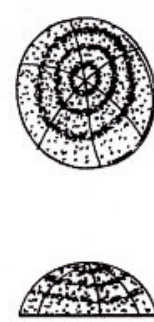

A
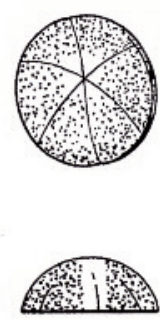

B
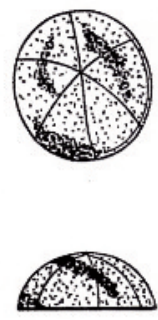

C
Figure A-6. Examples of sapphires with undesirable color and color zoning that can be altered by diffusion treatment: (A) color banding, (B) a clear center, and (C) off-color, irregularly distributed color banding. After German published patent application DE 2262 104A. Inventors: R.R. Carr and S.D. Nisevich (1973c); applicant: Astrid Corporation.

Eversole and Burdick's patent (1954c) stated that even nonasteriated natural cabochons could be treated to produce asterism by the diffusion technique so invented. In one example, the treatment of "pale blue-green unasteriated nat- 
TABLE A-1. Patent documents related to production or enhancement of asterism in corundum.

\begin{tabular}{|c|c|c|c|c|}
\hline Author(s)/applicant & $\begin{array}{c}\text { U.S. patent } \\
\text { documents/ } \\
\text { publication year }\end{array}$ & $\begin{array}{l}\text { Related patents (patent } \\
\text { family)/publication year }\end{array}$ & Purpose & Technical details \\
\hline $\begin{array}{l}\text { J.N. Burdick and J.W. } \\
\text { Glenn (Linde Air Products } \\
\text { Company) }\end{array}$ & $\begin{array}{l}\text { US 2,488,507 } \\
(1949)\end{array}$ & & $\begin{array}{l}\text { Manufacture of } \\
\text { asteriated ruby and } \\
\text { sapphire }\end{array}$ & $\begin{array}{l}\text { Growth of titanium-doped } \\
\text { corundum and subsequent } \\
\text { annealing of the synthetic boule } \\
\text { at temperatures between } 1500^{\circ} \\
\text { and } 1100^{\circ} \mathrm{C} \text { to form precipitates } \\
\text { of a titanium compound }\end{array}$ \\
\hline $\begin{array}{l}\text { J.N. Burdick and R.A. Jones } \\
\text { (Union Carbide and } \\
\text { Carbon Corporation) }\end{array}$ & $\begin{array}{l}\text { US 2,690,062 } \\
\text { (1954a) }\end{array}$ & $\begin{array}{l}\text { DE } 897844(1954 b) \\
\text { DE } 948403(1956) \\
\text { GB } 697,804(1953 b) \\
\text { FR 1.029.418 (1953a) } \\
\text { CH } 289320(1953 c)\end{array}$ & $\begin{array}{l}\text { Manufacture of } \\
\text { asteriated ruby and } \\
\text { sapphire with } \\
\text { homogeneous color } \\
\text { distribution and } \\
\text { complete six-rayed stars }\end{array}$ & $\begin{array}{l}\text { Increasing the homogeneity of } \\
\text { titanium distribution within the } \\
\text { Verneuil boule, crystal growth } \\
\text { under fluctuating thermal } \\
\text { conditions }\end{array}$ \\
\hline $\begin{array}{l}\text { W.G. Eversole and J.N. } \\
\text { Burdick (Union Carbide } \\
\text { and Carbon Corporation) }\end{array}$ & $\begin{array}{l}\text { US 2,690,630 } \\
(1954 \mathrm{c})\end{array}$ & $\begin{array}{l}\text { DE } 922584(1955 a) \\
\text { GB } 712,735 \text { (1954a) } \\
\text { FR } 1.067 .037(1954 b) \\
\text { CH } 307914 \text { (1955b) }\end{array}$ & $\begin{array}{l}\text { Production of asterism } \\
\text { in natural or synthetic } \\
\text { corundum }\end{array}$ & $\begin{array}{l}\text { Diffusion of titanium into a thin } \\
\text { surface layer of a ruby or } \\
\text { sapphire crystal at temperatures } \\
\text { between } 1950^{\circ} \text { and } 1700^{\circ} \mathrm{C} \text { and } \\
\text { subsequent annealing of the } \\
\text { corundum crystal at } \\
\text { temperatures between } 1500^{\circ} \\
\text { and } 1100^{\circ} \mathrm{C} \text { to form precipitates } \\
\text { of a titanium compound }\end{array}$ \\
\hline $\begin{array}{l}\text { G.A. Keig, J.C. Smith, and } \\
\text { J.M.J. Watts (Union } \\
\text { Carbide Corporation) }\end{array}$ & $\begin{array}{l}\text { US } 3,655,415 \\
(1972) \\
\text { US 3,725,092 } \\
(1973 a)\end{array}$ & $\begin{array}{l}\text { DE } 2208150 A(1973 c) \\
\text { GB } 1377428(1974) \\
\text { FR } 2.172 .913(1973 d) \\
\text { CH } 539581(1973 b) \\
\text { AT } 327863(1976)\end{array}$ & $\begin{array}{l}\text { Manufacture of } \\
\text { asteriated ruby and } \\
\text { sapphire with } \\
\text { homogeneous color } \\
\text { distribution and } \\
\text { complete six-rayed stars } \\
\text { in any desired size }\end{array}$ & $\begin{array}{l}\text { Growth of titanium-doped } \\
\text { corundum by the Czochralski } \\
\text { technique and subsequent } \\
\text { annealing of the synthetic crystal } \\
\text { at temperatures between } 1500^{\circ} \\
\text { and } 1100^{\circ} \mathrm{C} \text { to form precipitates } \\
\text { of a titanium compound }\end{array}$ \\
\hline $\begin{array}{l}\text { R.R. Carr and S.D. Nisevich } \\
\text { (Union Carbide Corporation) } \\
\text { R.R. Carr and S.D. Nisevich } \\
\text { (Astrid Corporation, Ltd.) } \\
\text { R.R. Carr and S.D. Nisevich } \\
\text { (Astrid Corporation, Ltd.) }\end{array}$ & $\begin{array}{l}\text { US 3,897,529 } \\
(1975 a) \\
\text { US 3,950,596 } \\
(1976 a) \\
\text { US 4,039,726 } \\
(1977)\end{array}$ & $\begin{array}{l}\text { DE } 2262104 A(1973 c) \\
\text { GB } 1408648(1975 b) \\
\text { FR 2.164.690 (1973a) } \\
\text { CH } 554811(1974) \\
\text { AT } 330722(1976 b) \\
\text { BE } 793.007(1973 b)\end{array}$ & $\begin{array}{l}\text { Production of } \\
\text { homogeneous color } \\
\text { distribution or altering } \\
\text { the appearance of color } \\
\text { in asteriated and non- } \\
\text { asteriated natural or } \\
\text { synthetic corundum }\end{array}$ & $\begin{array}{l}\text { Diffusion of titanium, diffusion of } \\
\text { another transition metal, or } \\
\text { diffusion of titanium together } \\
\text { with another transition metal into } \\
\text { a thin surface layer of a ruby or } \\
\text { sapphire crystal at temperatures } \\
\text { between } 1850^{\circ} \text { and } 1600^{\circ} \mathrm{C} \text {; to } \\
\text { produce asteriated corundum, } \\
\text { subsequent annealing of the } \\
\text { synthetic crystal at temperatures } \\
\text { between } 1500^{\circ} \text { and } 1100^{\circ} \mathrm{C} \text { to } \\
\text { form precipitates of a titanium } \\
\text { compound }\end{array}$ \\
\hline
\end{tabular}

US-United States; DE-Germany; GB-United Kingdom; FR-France; CH-Switzerland; AT-Austria; BE-Belgium

ural sapphire" is mentioned, which indicates that diffusion treatment of natural sapphire to produce asterism has been known since 1954.

The diffusion process of Eversole and Burdick (1954c) was extended by Carr and Nisevich (1975a, 1976a, 1977) for altering the color appearance of natural and synthetic corundum. Through the use of diffusion processes as described in the patent documents (figure A-5), various uneven or undesired color distributions (figure A-6) of natural or synthetic, asteriated or non-asteriated ruby and sapphire crystals can be enhanced. Based on the intended final coloration, oxides of transition metals such as titanium, vanadium, chromium, iron, or nickel, alone or in combination, are diffused into the corundum sample. If asterism is to be developed or enhanced, in addition to the desired color improvement, a second low-temperature annealing step is always required to produce the necessary oriented titanium-bearing precipitates. 


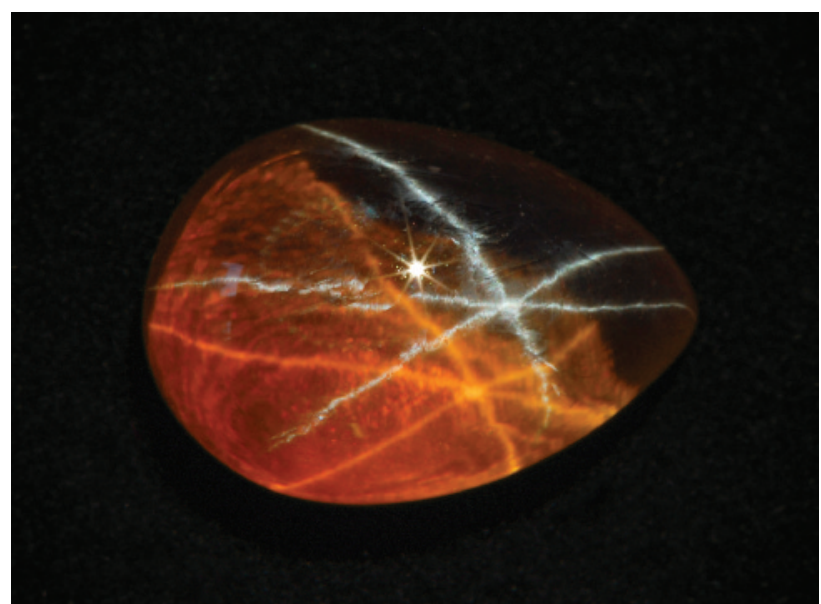

Figure 4. This brownish yellow synthetic sapphire showing a white six-rayed star and a brownish yellow star was purchased by one of the authors in Bangkok in 2010. The cabochon measures $14.2 \times 9.8 \mathrm{~mm}$ and weighs $9.76 \mathrm{ct}$. Photo courtesy of M.P. Steinbach.

\section{SAMPLE TYPES AND EXAMINATION METHODS}

The present study started with the examination of 15 asteriated synthetic rubies and sapphires of different colors that were purchased by one of the authors (MPS) in Bangkok in 2010 for his personal collection (figure 4). Neither the producer nor any details of the production technique were disclosed. An Internet search revealed that the company Thai Star Sapphire, based in Ladprao, Bangkok, is producing and offering synthetic stones of the complete color series so acquired and available for the present study (see "Thai star sapphire," n.d.). An additional extraordinarily large sample of that material, weighing $91 \mathrm{ct}$, was purchased in Bangkok in December 2014.

Similar transparent, diffusion-treated samples were made available from Wiede's Carbidwerk in Freyung, Germany, both from their production in the 1970s and from recent production. The authors were also able to examine two synthetic asteriated rubies cut in Idar-Oberstein, Germany, from the recent production of Hrand Djevahirdjian SA, one of the largest manufacturers of synthetic corundum and located since 1914 in Monthey, Switzerland.

To compare the foregoing types of samples with materials produced by Linde, the latter of which have been discussed in the literature, we collected and examined several series of asteriated Linde rubies and sapphires from different collections and the trade in the UK and Germany. Most of these 26 samples had been kept in private collections since the 1970s or before (see also box C). One of the Linde sapphire cabochons had been removed from vintage jewelry.
An Internet search further revealed that samples presently available in the gem and jewelry market under the trade name "Linde" include: (1) samples removed from vintage jewelry that had contained stones originally produced by Linde or the Linde division of Union Carbide; (2) "old stock" samples, without previous jewelry use, likewise manufactured by Linde before the production stopped and crystal growth and/or marketing was transferred to Astrid Corporation of Hong Kong in the 1970s; and (3) asteriated synthetic rubies and sapphires of various colors produced recently in Asia or elsewhere but marketed as "Linde." The "Linde" trademark has been owned by Charles and Brenda Cook of the United States since they acquired rights to the name in 2007 (C. Cook, pers. comm., 2014).

For the present investigation, we were able to purchase some Linde "old stock" material produced originally in the 1970s or before in the United States. These 66 samples can be traced back to a former employee of Union Carbide (D.L. Snyder, pers. comm., 2014).

The material currently marketed in the United States under the Linde name but obtained from Asian sources by the American distributor is represented by 13 samples. The majority of these synthetic rubies and sapphires were purchased by the distributor in Hong Kong as ready-made cabochons. The remaining cabochons offered a sampling of the distributor's acquisitions of similar material from other Asian markets such as India, Thailand, and mainland China (C. Cook, pers. comm., 2014).

The synthetic corundum samples from this study are summarized in table 2.

In addition to the foregoing synthetic corundum samples, we were able to examine a natural sapphire with a dual-color double-star pattern from the collection of one of the authors (MPS).

To augment the work with synthetic and natural corundum, we examined two almost colorless, slightly pink rose quartz cabochons from Brazil and two similar asteriated slightly brownish pink quartz stones from India, each of which showed the phenomenon of dual-color double stars. These samples came from the same author's collection.

All corundum and quartz samples were examined in a Schneider immersion microscope with Zeiss optics (up to $100 \times$ magnification). To better resolve acicular inclusions, the natural sapphire and four of the synthetic corundum cabochons were examined at higher magnification (up to 1000x) in reflected and transmitted light using a Leitz Ortholux II Pol-BK polarization 


\begin{tabular}{|c|c|c|c|c|}
\hline $\begin{array}{l}\text { Number of } \\
\text { samples }\end{array}$ & Source & Producer & $\begin{array}{l}\text { Opaque samples } \\
\text { without double } \\
\text { stars }\end{array}$ & $\begin{array}{l}\text { Transparent or } \\
\text { translucent samples } \\
\text { with double stars }\end{array}$ \\
\hline 15 & $\begin{array}{l}\text { Gem trade in Bangkok, Thailand, } \\
2010\end{array}$ & Unknown & & $\checkmark$ \\
\hline 1 & $\begin{array}{l}\text { Gem trade in Bangkok, Thailand, } \\
2014\end{array}$ & Unknown & & $\checkmark$ \\
\hline 13 & $\begin{array}{l}\text { C. and B. Cook, Silk Purse Jewelry } \\
\text { (Palmetto, Florida), } 2013\end{array}$ & $\begin{array}{l}\text { Sold under the trade } \\
\text { name "Linde" in the } \\
\text { United States, but } \\
\text { purchased on various } \\
\text { Asian markets from } \\
\text { unknown producers }\end{array}$ & $\checkmark$ & $\checkmark$ \\
\hline 4 & $\begin{array}{l}\text { H. Schulz, Wiede's Carbidwerk } \\
\text { (Freyung, Germany), } 2014\end{array}$ & $\begin{array}{l}\text { Wiede's Carbidwerk } \\
\text { (Freyung, Germany) }\end{array}$ & & $\checkmark$ \\
\hline 2 & $\begin{array}{l}\text { M. Kämmerling (Idar-Oberstein, } \\
\text { Germany), } 2014\end{array}$ & $\begin{array}{l}\text { Hrand Djevahirdjian SA } \\
\text { (Monthey, Switzerland) }\end{array}$ & $\checkmark$ & $\checkmark$ \\
\hline 8 & C. Cavey (London, UK) & $\begin{array}{l}\text { Linde/Union Carbide, } \\
\text { (New York) }\end{array}$ & $\checkmark$ & \\
\hline 3 & M.P. Steinbach (Idar-Oberstein) & Linde/Union Carbide & $\checkmark$ & \\
\hline 13 & $\begin{array}{l}\text { A. Hodgkinson (Portencross, } \\
\text { Scotland) }\end{array}$ & Linde/Union Carbide & $\checkmark$ & $\checkmark$ \\
\hline 2 & L. Gleave, Gem-A (London, UK) & Linde/Union Carbide & & $\checkmark$ \\
\hline $6+60$ & $\begin{array}{l}\text { D.L. Snyder, The Brazilian } \\
\text { Connection (Benton, Pennsylvania), } \\
2013\end{array}$ & Linde/Union Carbide & $\checkmark$ & $\checkmark$ \\
\hline
\end{tabular}

microscope. The investigation at high magnification was also performed for the four quartz cabochons.

To evaluate the possible influence of diffusiontreated layers on the formation of asterism, we removed thin layers of corundum material from the flat or slightly curved base of several synthetic cabochons and investigated for any change in the appearance of the samples. This grinding and repolishing process was performed up to three times. Similar procedures were applied to the curved dome of other samples.

The "old stock" Linde material included six finished and polished cabochons and a lot of 60 partially finished synthetic ruby and sapphire cabochons of varied quality and appearance. Among the partially finished cabochons without a detailed history of the production processes applied was a subgroup having what appeared to be inhomogeneous crusts on the surface. Seven samples from this subgroup were selected for chemical analysis by Xray fluorescence spectroscopy using a Bruker Tracer III-SD handheld unit. A further analysis of the distribution of trace elements for five samples of this subgroup was performed by X-ray fluorescence mapping using a Bruker M4 Tornado scanning micronscale X-ray fluorescence $(\mu-\mathrm{XRF})$ system. The diameter of the incident beam applied for the mapping process was $25 \mu \mathrm{m}$.

To characterize needle-like inclusions and the cause of asterism in the brownish pink and rose quartz samples, we employed micro-Raman spectroscopy using an XploRA confocal Raman microscope facility from Horiba with a $532 \mathrm{~nm}$ laser. 


\section{RESULTS}

Natural Purplish Pink Sapphire from Myanmar. Most natural asteriated rubies and sapphires are opaque or only slightly translucent and do not reveal the dual-color double stars that are the focus of this study. However, a transparent purplish pink sapphire, said to originate from Mogok, Myanmar, proved more relevant for the present research.

The gemstone showed two clearly separated sixrayed stars: one white star reflected from the dome of the cabochon and one purplish pink star confined to the curved base of the sample (figure 5). In reflected light, the white and the bodycolored star were each visible regardless of the direction of view-i.e., when viewed toward the dome of the sample and when viewed toward the curved base (figure 6). Moreover, in each viewing geometry, the bodycolored star was focused within the cabochon, and the white star was focused slightly outside the cabochon, between the sample and the observer.

Rutile needles in three orientations were discerned within all parts of the stone, but the rutile framework showed an irregular, patchy zoning with a variable concentration of needles in different parts of the sapphire. Specifically, certain growth planes parallel to the hexagonal prism $a\{11 \overline{2} 0\}$ and parallel to the hexagonal dipyramid $n\{22 \overline{4} 3\}$ exhibited a denser concentration of rutile needles (figure 7). These planes were identified in the immersion microscope by determining the angle formed by the growth planes with the optic axis of the sapphire.

At higher magnification, it was observed that the

Figure 5. This purplish pink sapphire from Myanmar shows a white star reflected from the dome of the cabochon and a bodycolored star reflected from the curved base of the sample; views to the center of the dome (left) and oblique to the center of the dome (right). The sample measures $7.0 \mathrm{~mm}$ in diameter and weighs $1.62 \mathrm{ct}$. Photos by K. Schmetzer.
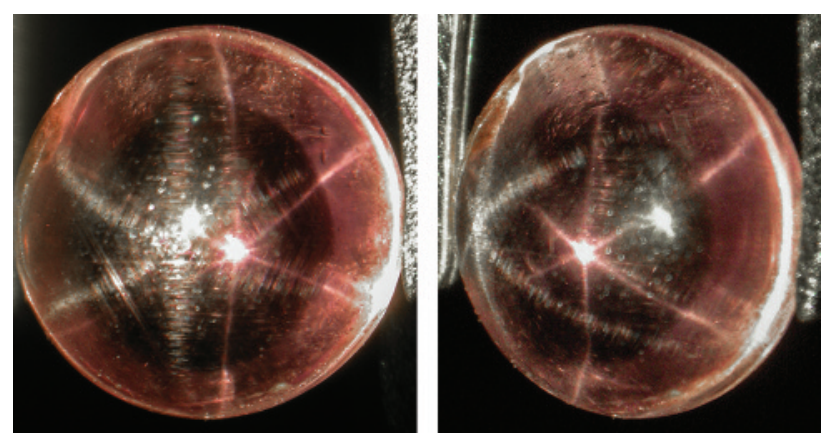
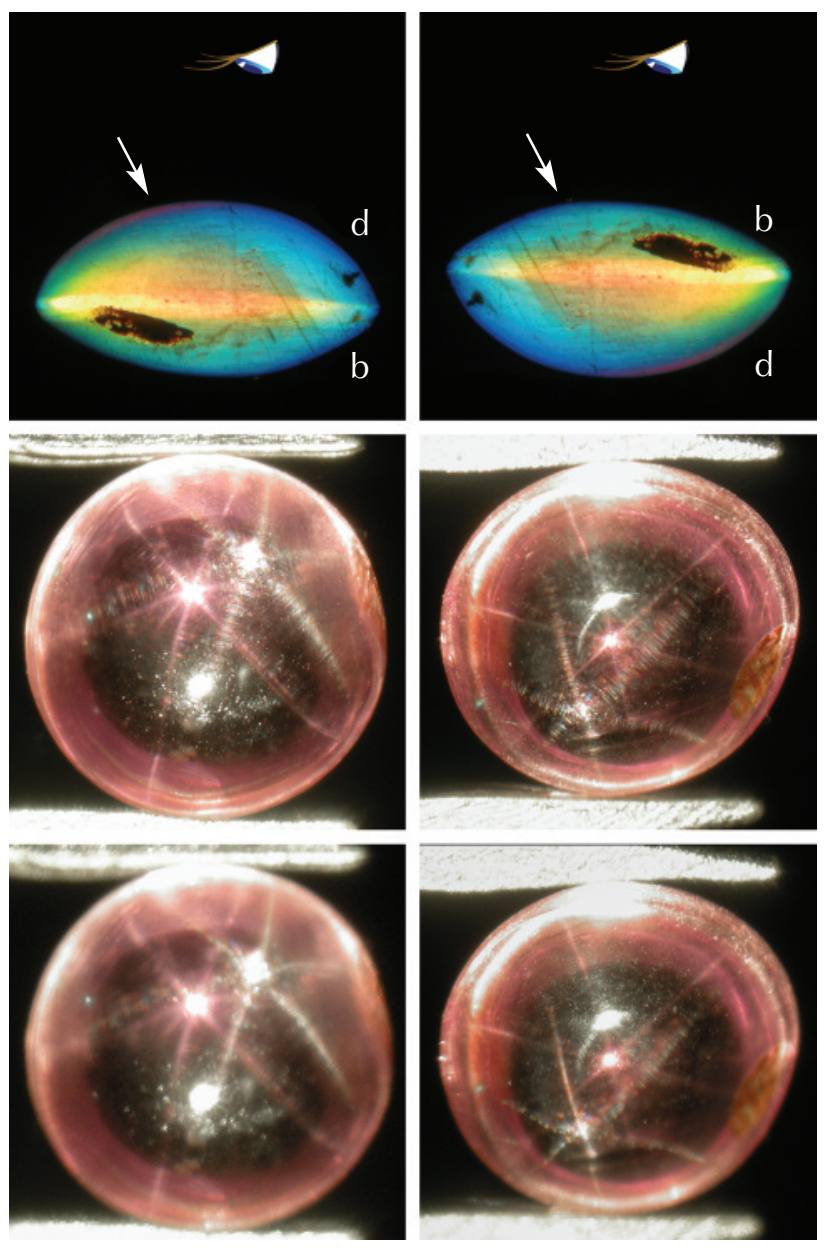

Figure 6. Purplish pink sapphire from Myanmar in a view to the curved dome (d) (left column) and the curved base (b) of the cabochon (right column). In the top row, the white arrow indicates the direction of light, and the eye symbolizes the observer receiving the reflected light. In both orientations, the bodycolored six-rayed star is focused within the cabochon (middle row), and the white star is focused slightly outside the stone, between surface and observer (bottom row). The sample measures $7.0 \mathrm{~mm}$ in diameter, with a thickness of $3.5 \mathrm{~mm}$, and weighs $1.62 \mathrm{ct}$. Photos by K. Schmetzer.

sapphire contained two types of needle-like inclusions. The first type (figures 8A-8C) consisted of needles up to $100 \mu \mathrm{m}$ in length with a thickness of 0.3 to $2 \mu \mathrm{m}$. The second type of needles consisted of crystals that were mostly twinned, with a length between 50 and $200 \mu \mathrm{m}$ and a thickness in the range of 5 to $10 \mu \mathrm{m}$. The twins were primarily V-shaped (figures $8 \mathrm{~A}, \mathrm{~B}, \mathrm{D}$, and E) and rarely knee-shaped (figure $8 \mathrm{C})$. Occasionally, the needles were twinned along the needle axis, showing a distinct re-entrant angle 


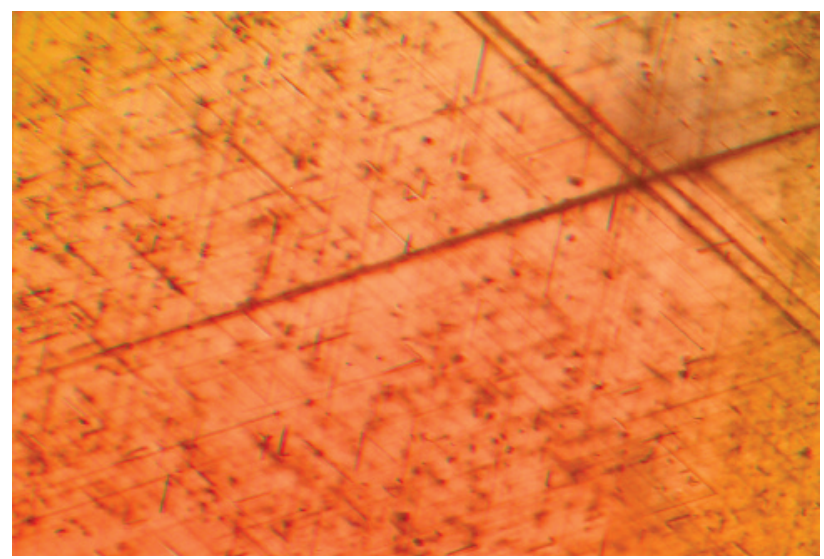

Figure 7. A framework of rutile needles in a purplish pink sapphire from Myanmar. In a view exactly parallel to the c-axis, several intersecting planes parallel to the hexagonal prism a with a high concentration of needles are visible. Immersion, field of view $2.8 \times 2.1$ $\mathrm{mm}$. Photo by K. Schmetzer.

at the end of the needle (figure $8 \mathrm{~F}$ ). This latter type of twinning has been characterized in several papers by electron microscopic examination combined with electron diffraction, generally in synthetic ruby or sapphire (Phillips et al., 1980; Moon and Phillips, 1991; Xiao et al., 1997; He et al., 2011). The twin plane of these rutile needles is (101), and the same twin plane is assumed for the V-shaped twins. This indicates, with a twin plane parallel to the needle axis, that the axis of these elongated twinned needles is not the c-axis of the rutile crystals.

Opaque Synthetic Corundum Samples with Single Stars. The different groups and lots of Linde rubies and sapphires examined (samples produced by Linde in the United States up to 1974 and those distributed presently under the Linde trade name) contained samples of the "normal" material without double stars, showing only one white six-rayed star confined to the dome of the cabochons. The samples of this group of mostly larger synthetic rubies and sapphires were principally opaque, with minimal if any translucency (again, see figure 1). Opaque synthetic rubies and sapphires originating from Asian markets and sold under the Linde name, but with unknown producer(s), were similar in appearance, as was one ruby from Hrand Djevahirdjian SA.
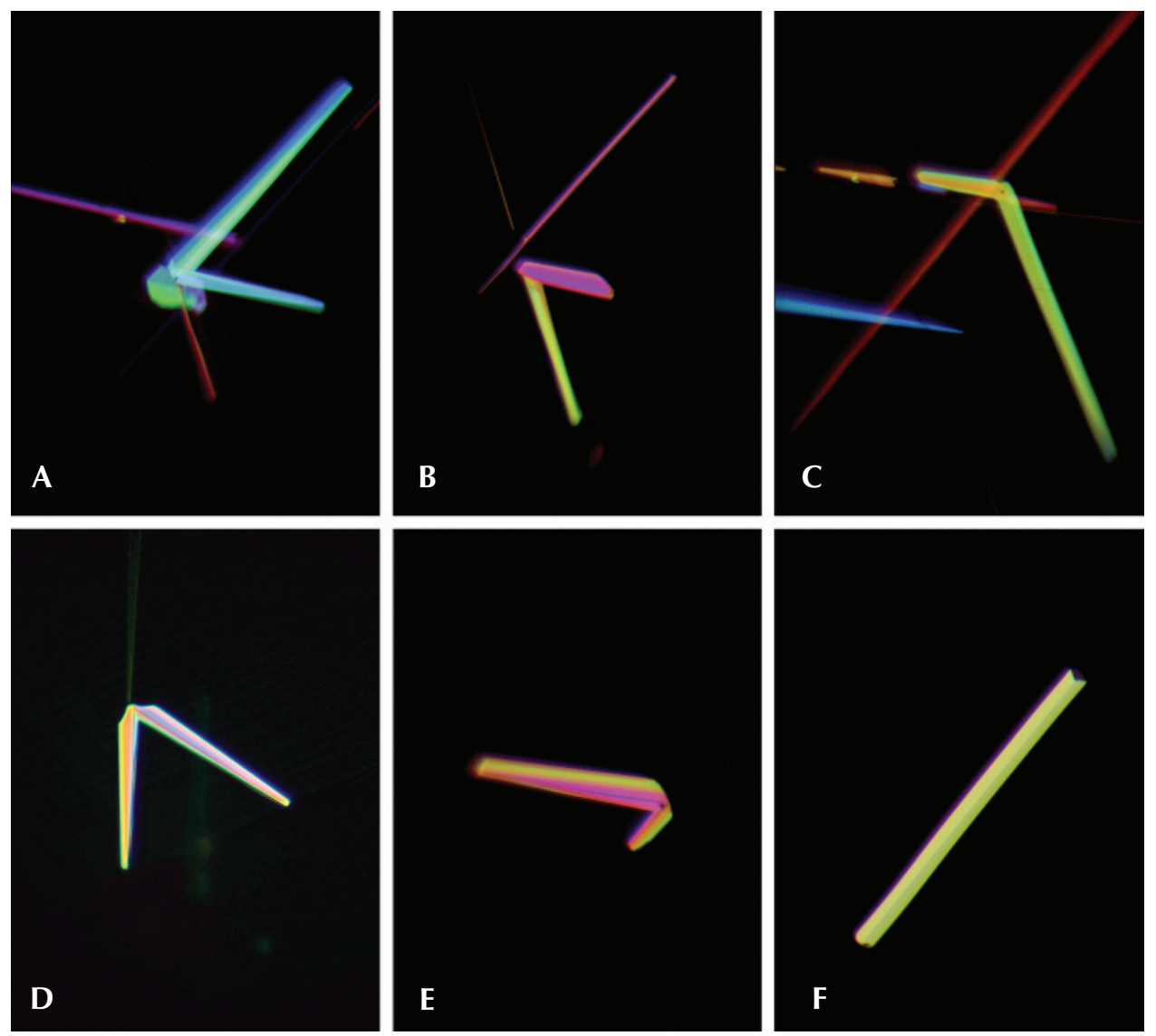

Figure 8. Rutile needles in the purplish pink sapphire from Myanmar. The sapphire contains one type of needles with a smaller diameter $(A, B, C)$ and a second type of somewhat thicker needles that are mostly twinned. This second type forms $V$-shaped twins $(A, B, D, E)$, knee-shaped twins (C), or needles that are twinned along the needle axis (F). Reflected light, oil immersion; field of view $112 \times 168$ um. Photos by H.-J. Bernhardt. 

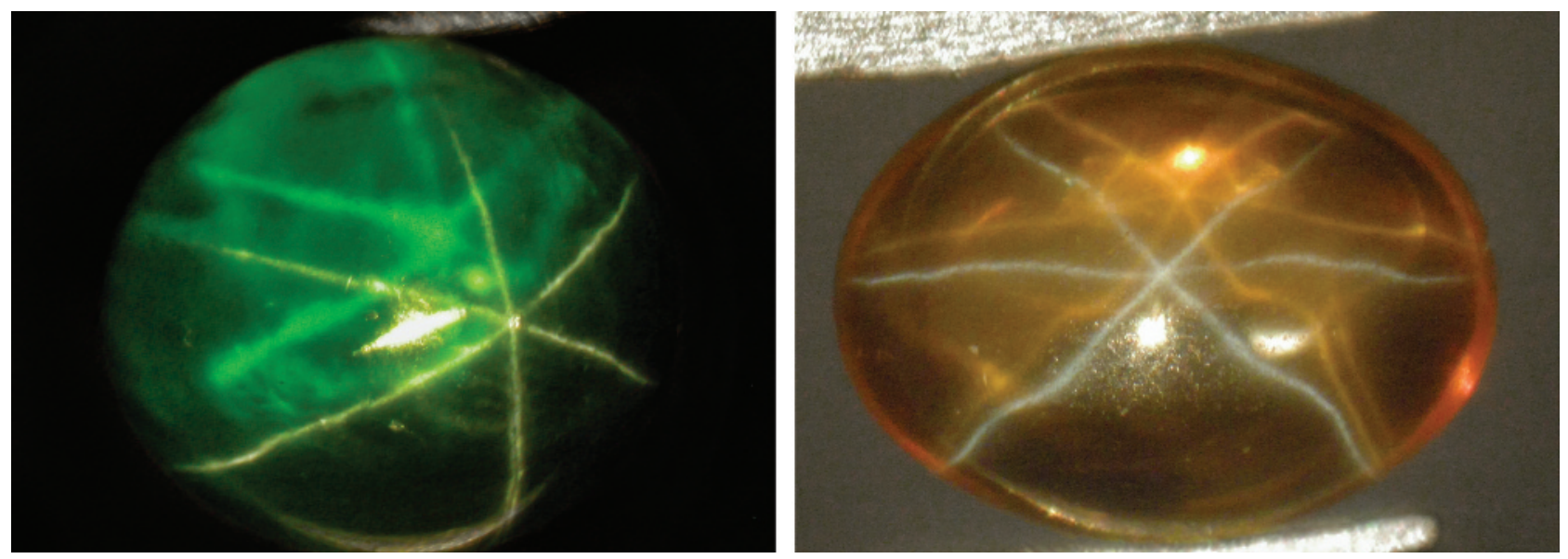

Figure 9. These two synthetic sapphires show a white six-rayed star and a bodycolored star; the arms of the two stars seem to intersect with each other and meet again at the transition between dome and base of the cabochon. The green cabochon measures $15.6 \times 14.1 \mathrm{~mm}$ and weighs $26.80 \mathrm{ct}$; the orange cabochon measures $10.0 \times 8.0 \mathrm{~mm}$ and weighs $3.85 \mathrm{ct}$. Photos by K. Schmetzer.

Upon microscopic examination with intense illumination, especially in immersion, a dense concentration of gas bubbles was observed, which frequently showed a distinct curved zoning consisting of layers with different concentrations of bubbles. Furthermore, irregularly curved boundaries, sometimes designated as "grain boundaries" or "subgrain boundaries" in the literature, were seen in most samples. Such boundaries may be explained by the fact that different parts of the crystals have slightly different orientations. Intersecting glide planes, commonly referred to by gemologists as Plato lines, were likewise evident in many samples. No needle-like inclusions were resolved with the magnification of the gemological microscope. Properties that would be uncommon for Verneuil-grown samples were absent.

The remainder of this section describes properties of various groups of transparent to translucent synthetic rubies and sapphires with dual-color double stars.

Synthetic Samples of Recent Production Originating from Asian Markets. This part describes two groups of synthetic materials that were purchased by the authors, one in Bangkok in 2010 and 2014 and the other in the United States (sold under the Linde trademark) in 2013. Both groups consisted mostly of transparent samples that showed two stars of different colors.

Synthetic Samples Purchased in Bangkok in 2010 and 2014. The 16 transparent synthetic rubies and sapphires that had been purchased in Bangkok were subdivided into two groups. A smaller group of three samples consisted of mixed-cut corundum with a polished curved upper part (dome) and a faceted back. These samples exhibited only the three intersecting light bands of an ordinary white six-rayed star, as is commonly seen in asteriated rubies and sapphires from various producers. The larger group of 13 contained samples fashioned with a polished curved dome and an almost rough (i.e., only lightly polished) and slightly curved to nearly flat base. Under fiberoptic illumination, all 13 samples of this group revealed one white six-rayed star and, in addition, three intersecting light bands producing a second, variously colored six-rayed star (figure 9; see also figure 4).

The ordinary white star was confined to the dome of the cabochons. In all samples, the second six-rayed star showed the bodycolor of the host corundum crystals (e.g., red, orange, yellow, or green). When these cabochons were illuminated through the center of the dome in a direction nearly perpendicular to the base and viewed parallel to the incident light, both stars showed the same orientation and overlapped each other. In contrast, when illuminated and/or viewed obliquely, both stars were clearly separated, and the bodycolored star seemed to emanate from the curved or almost flat, slightly polished base of the cabochon. The arms of both stars appeared to meet at the transition between dome and base (figure 9, right).

Under the microscope, it could be observed that the white star was focused slightly above the curved dome of the cabochons. The bodycolored star was focused below the white star and dome, within the body of the cabochon (figure 10). This effect was particularly noticeable in samples with a relatively high dome or cut with a broad girdle. 

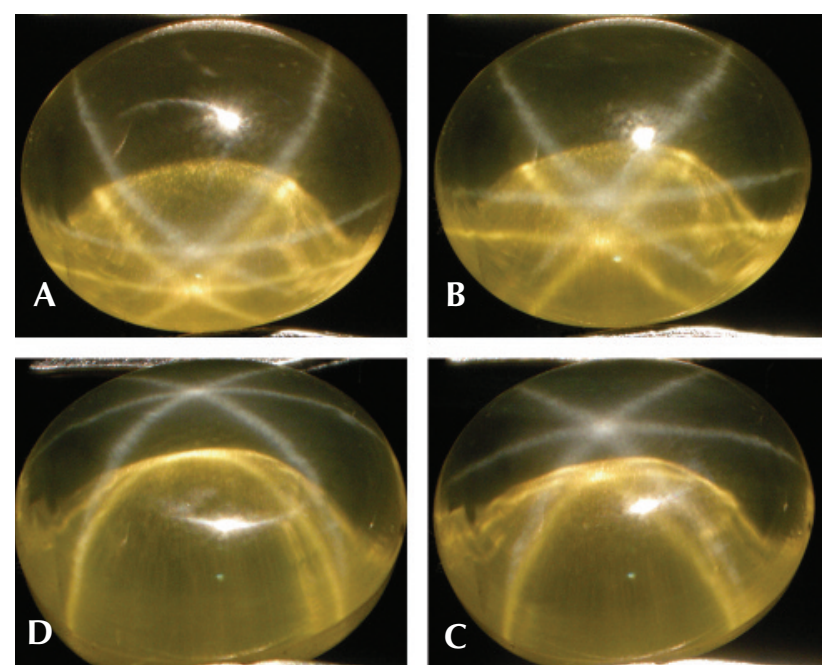

Figure 10. This yellow synthetic sapphire shows a sixrayed white and a yellow star. Upon rotation using an east-west oriented rotation axis (sequence from $A$ to $D)$, it is observed that the yellow star reflected from the base is focused below the white star, within the cabochon. The sample measures $11.8 \times 9.8 \mathrm{~mm}$, with a thickness of $7.0 \mathrm{~mm}$ (girdle about $3.8 \mathrm{~mm}$ ), and weighs 10.08 ct. Photos by K. Schmetzer.

Microscopic examination also revealed internal characteristics, with most samples showing irregularly curved grain boundaries, best seen with crossed polarizers in immersion (figure 11, left and center). Some of these boundaries displayed interference colors, thereby establishing the slightly different orientations between different parts of the crystals. In addition, some of the corundum samples contained intersecting glide planes or Plato lines (figure 11, right). Sharp curved growth striations, characteristic of
Verneuil-grown corundum, were observed in the rubies but not in the differently colored sapphires. Some of these synthetic sapphires showed only somewhat diffuse, curved growth lines, and a portion of the samples did not reveal any curved growth striations at all. Gas bubbles were seen only in two of the sapphires.

All microscopic features observed in the 16 rubies and sapphires typically characterize synthetic corundum crystals grown by the Verneuil method. Oriented needles were not discernible under the magnification of the gemological microscope.

In order to clarify which parts of the samples contained three series of small needles, the mechanism considered responsible for the production of six-rayed asterism and presumed to generate the white and the bodycolored stars examined here, we ground and repolished the slightly curved or almost plane base of four asteriated cabochons, as well as the dome of another synthetic sapphire.

After grinding and repolishing the base of the four cabochons, all samples showed only one remaining white six-rayed star (figure 12, left). The bodycolored star was no longer visible. Conversely, after grinding and repolishing the curved dome of the other cabochon, this sample showed only the second six-rayed star with the bodycolor of the sapphire, and the ordinary white star had disappeared (figure 12, right).

Synthetic Samples Purchased in the United States in 2013, Originating from Various Asian Markets. The visual appearance of the transparent synthetics produced recently in Asia but sold in the United States under the Linde trade name was consistent with that of the 13 (non-faceted) Bangkok samples described above. They revealed a white six-rayed star

Figure 11. Microscopic features in Verneuil-grown diffusion-treated synthetic sapphires. Irregular grain boundaries are frequently observed under crossed polarizers (left and center); occasionally, glide planes (Plato lines) are also seen (right). Viewed in immersion; field of view: $8.1 \times 6.1 \mathrm{~mm}$ (left), $9.5 \times 7.2 \mathrm{~mm}$ (center), and $9.5 \times 7.2 \mathrm{~mm}$ (right). Photos by K. Schmetzer.
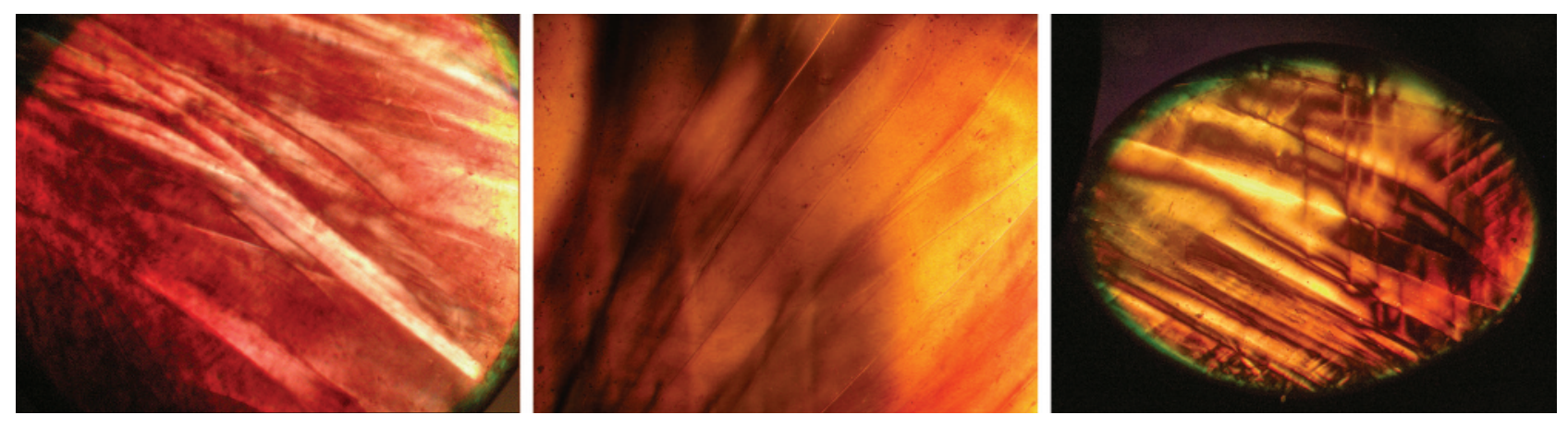

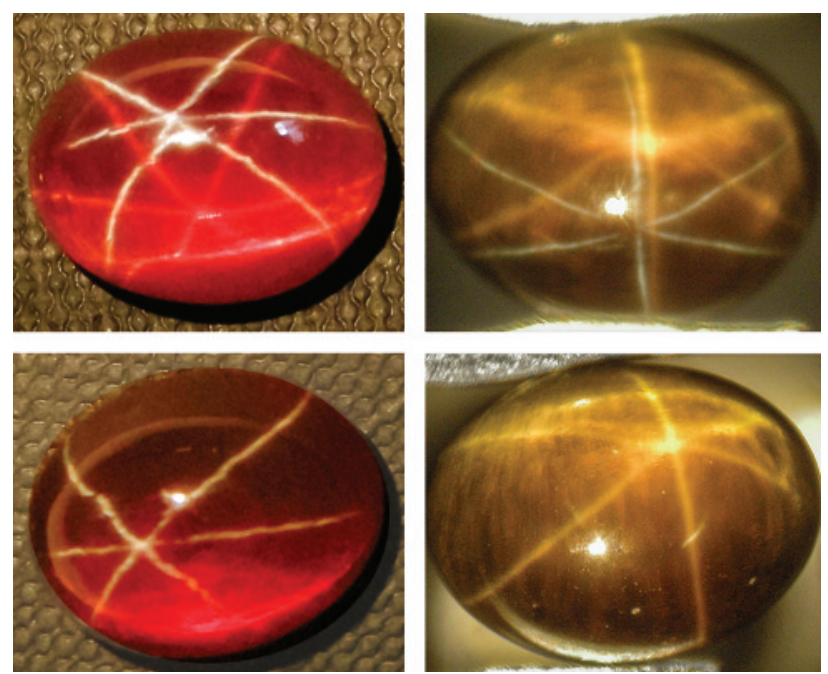

Figure 12. Left: This red-orange synthetic sapphire shows a white star and a red-orange star (top); after grinding and repolishing of the base, the red-orange star is removed and only the white star is observed (bottom). The sample measures $13.2 \times 10.4 \mathrm{~mm}$ and weighs 11.15 ct. Right: This light yellow-orange synthetic sapphire shows a white star and a yellow-orange star (top); after grinding and repolishing of the dome, the white star is removed and only the yellow-orange star remains (bottom). The sample measures $11.5 \times 8.7 \mathrm{~mm}$ and weighs $6.94 \mathrm{ct}$. Photos by K. Schmetzer.

related to the curved dome of the cabochon and a second star reflecting the bodycolor of the sample (i.e., red, yellow-orange, or orange; figure 13).

The microscopic pattern was also analogous to that of the samples purchased in Bangkok. The synthetic rubies and orange sapphires showed curved growth striations, occasionally related to a zoning of

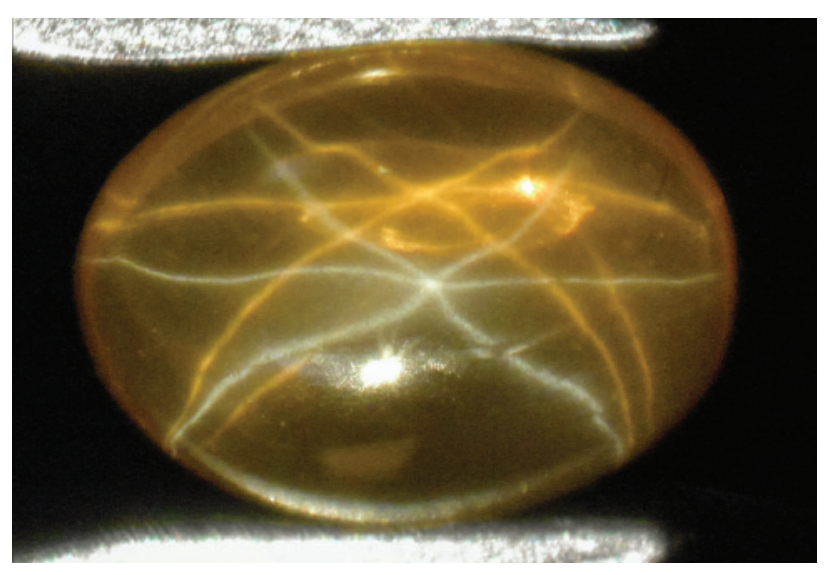

Figure 13. This yellow-orange synthetic sapphire shows a white six-rayed star and a yellow-orange star; this material is currently distributed under the "Linde" trade name. The sample measures $8.2 \times 6.2$ $\mathrm{mm}$ and weighs $1.46 \mathrm{ct}$. Photo by K. Schmetzer.

gas bubbles (figure 14, left and center). Irregular grain boundaries and Plato lines were also seen in some instances (figure 14, right).

From the transparent samples of this group, we selected two synthetic rubies for grinding and repolishing, one sample at the base and one sample at the curved dome. The alterations were similar to those seen in the group of Bangkok samples described earlier. For the ruby ground and repolished at the base, the red star reflecting the bodycolor of the crystal was completely removed (figure 15, left). For the sample repolished at the dome, the white star confined to the upper surface was no longer present (figure 15, right).

To investigate the formation of stars in transmitted light (diasterism), we examined some samples in their as-received state, with upper and lower diffused

Figure 14. Microscopic features in Verneuil-grown diffusion-treated synthetic rubies (left) and sapphires (center and right). Left: Synthetic ruby with curved growth lines and irregularly distributed gas bubbles. Center: Sapphire with curved zones showing different concentrations of gas bubbles. Right: Sapphire with irregularly shaped grain boundaries. Immersion, crossed polarizers; field of view: $4.5 \times 3.4 \mathrm{~mm}$ (left), $4.5 \times 3.4 \mathrm{~mm}$ (center), and $9.5 \times 7.2$ mm (right). Photos by K. Schmetzer.
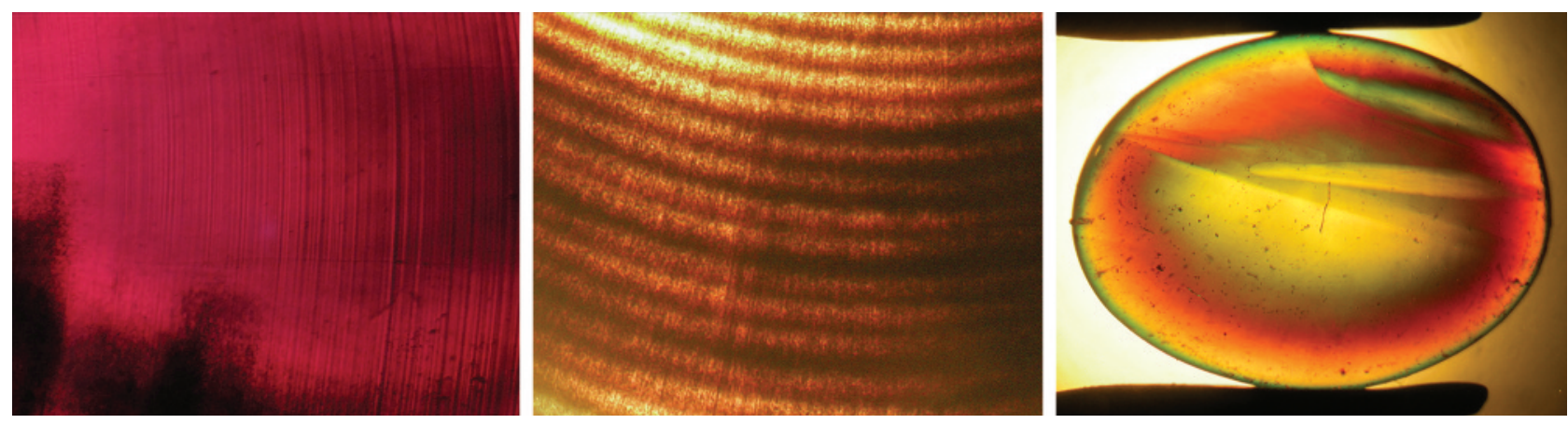

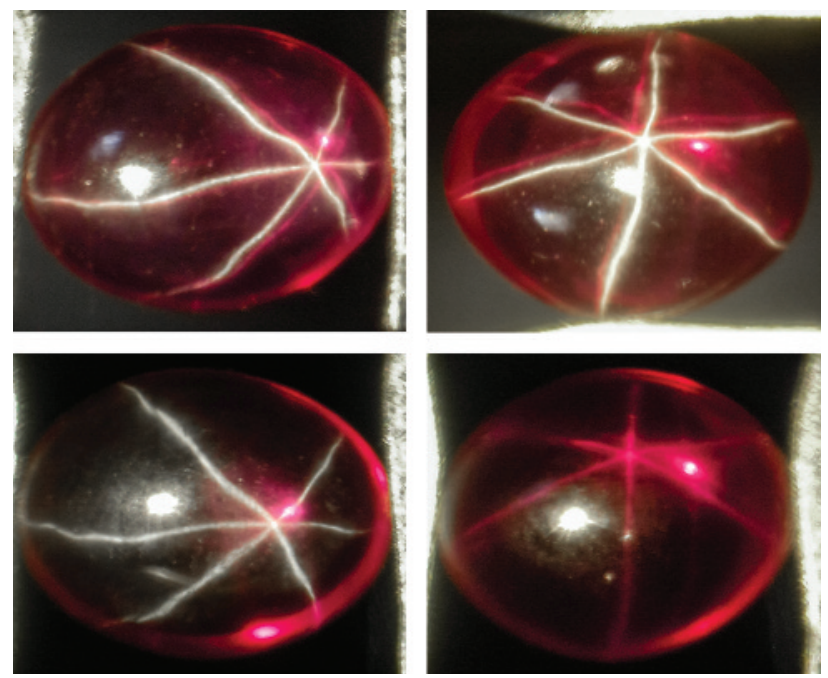

Figure 15. Left: This synthetic ruby shows a white star and a red-purple star (top); after grinding and repolishing of the base, the red-purple star is removed and only the white star remains (bottom). The sample measures $8.1 \times 6.3 \mathrm{~mm}$ and weighs 1.44 ct. Right: This synthetic ruby shows a white star and a red-purple star (top); after grinding and repolishing of the dome, the white star is removed and only the red-purple star remains (bottom). The sample measures $10.3 \times 8.1$ mm and weighs $3.51 \mathrm{ct}$. Photos by K. Schmetzer.

layers intact, and other samples that had been ground and repolished as indicated above, either:

1. At the dome of the sample, leaving a diffusiontreated layer at the base, or

2. At the base of the cabochon, leaving a diffusion-treated layer at the dome

Figure 16. In transmitted light, this yellow-orange synthetic sapphire shows a bodycolored six-rayed star; asterism in transmitted light is known as diasterism. The sample (see figure 13) measures $8.2 \times 6.2$ $\mathrm{mm}$ and weighs $1.46 \mathrm{ct}$. Photo by K. Schmetzer.

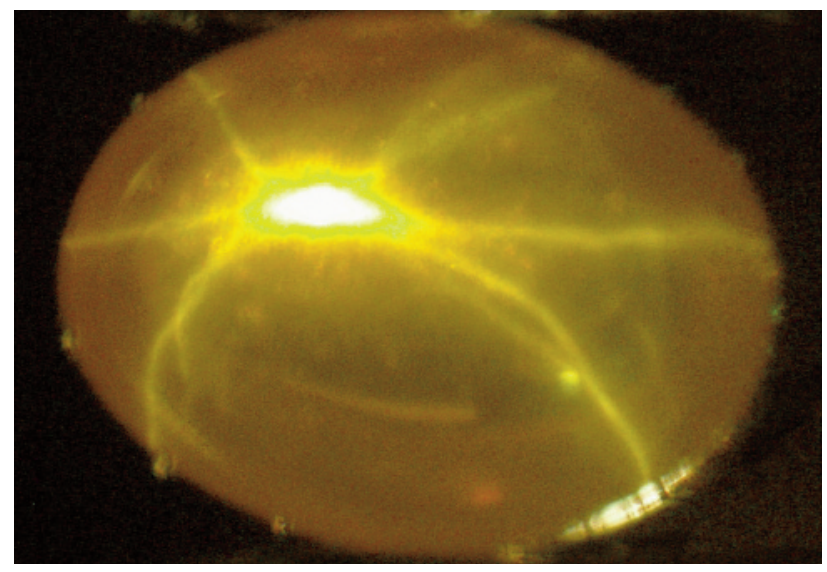

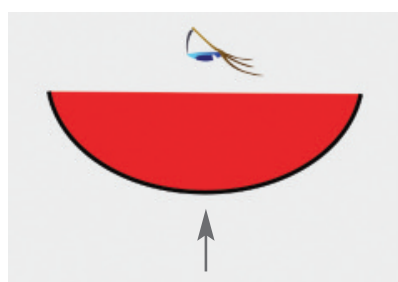
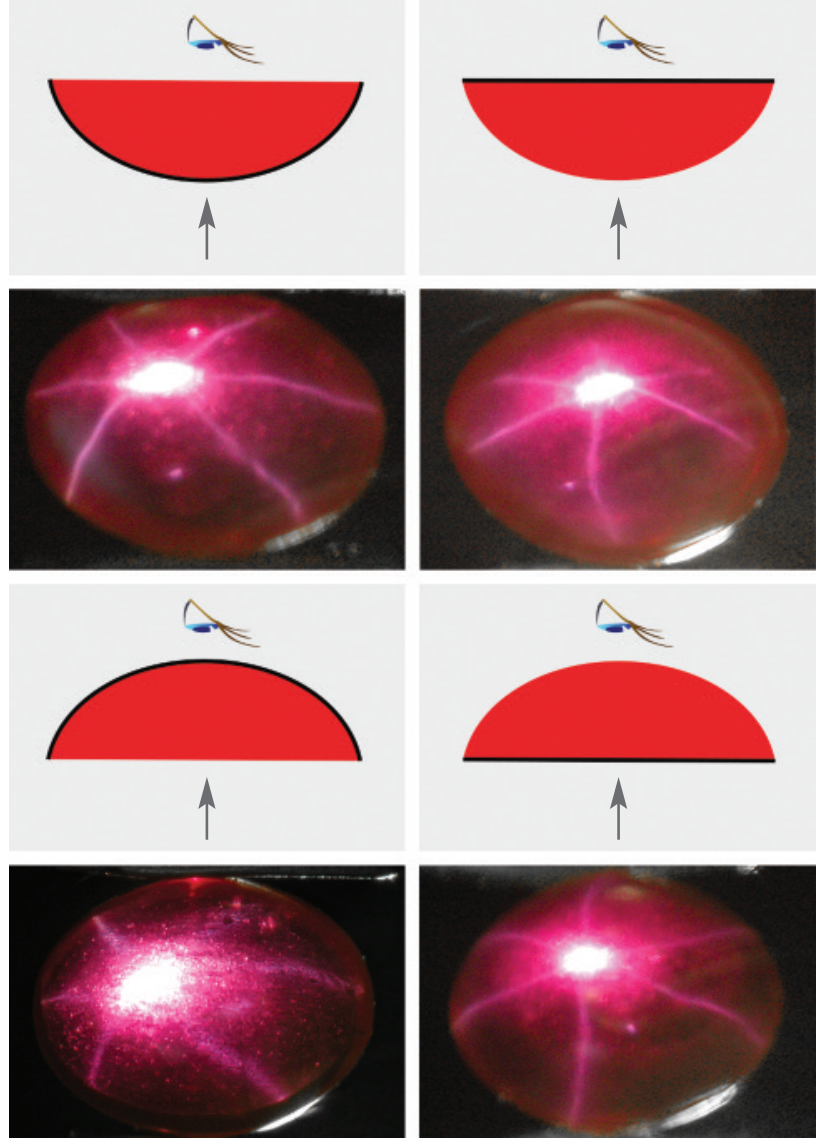

Figure 17. Diasterism is observed in transmitted light in diffusion-treated synthetic rubies that have been ground and repolished at the base (left sample) or at the dome (right sample). The remaining diffusiontreated layer with rutile needles is schematically shown in black, with the arrow indicating the direction of light and the eye symbolizing the observer. In all four views, a bodycolored red-purple six-rayed star is observed. The sample on the left measures $8.1 \times 6.3$ $\mathrm{mm}$ and weighs $1.44 \mathrm{ct}$ (see figure 15, left). The sample on the right measures $10.3 \times 8.1 \mathrm{~mm}$ and weighs $3.51 \mathrm{ct}$ (see figure 15, right). Photos by K. Schmetzer.

For all types of samples, comparative observations were made with the light impinging either on the curved dome or on the flat base of the cabochons.

Samples in the as-received state showed a single bodycolored six-rayed star in transmitted light (figure 16). The observations for ground and repolished rubies are summarized in figure 17. In all four conditions of view depicted, a single star was seen in transmitted light. This demonstrated that regardless of the path of the incident transmitted beam of light, a star is formed, even in samples having only a small diffused layer with rutile needles on one side of the 

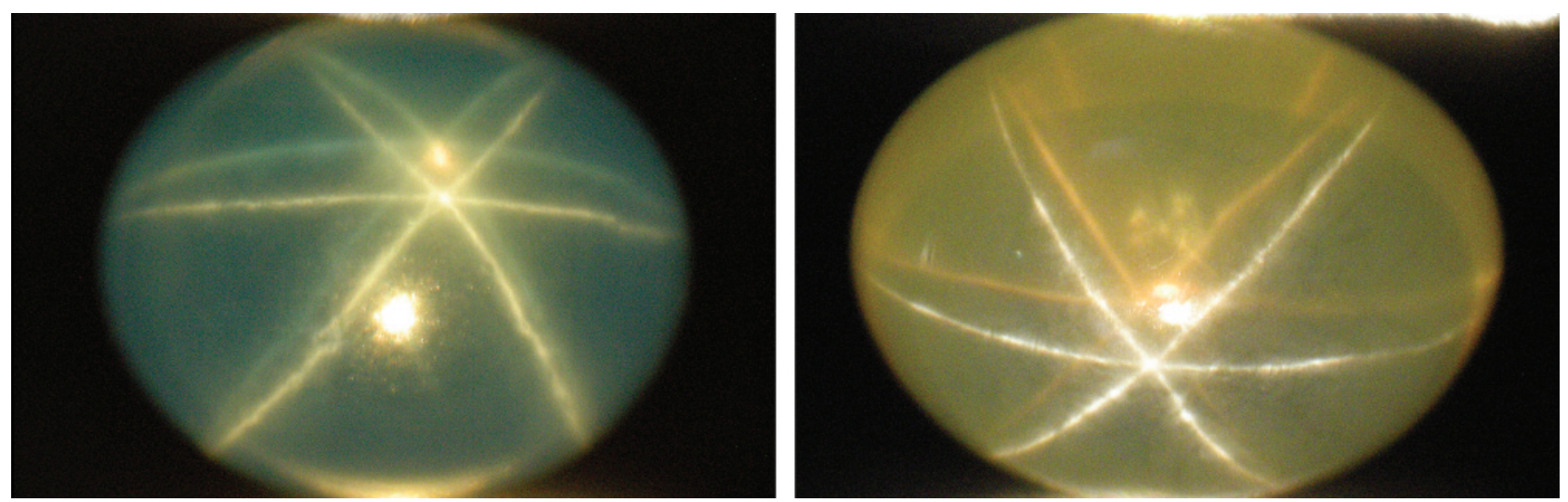

Figure 18. A diffusion-treated blue synthetic sapphire from recent production (left) and a diffusion-treated synthetic yellow sapphire produced in the 1970s (right), both manufactured by Wiede's Carbidwerk. Both show a white star and a bodycolored blue or yellow star. The blue cabochon measures $12.2 \times 10.2 \mathrm{~mm}$ and weighs $7.44 \mathrm{ct}$; the yellow cabochon measures $10.2 \times 8.0 \mathrm{~mm}$ and weighs $3.91 \mathrm{ct}$. Photos by K. Schmetzer.

cabochon, either at the flat or almost flat base or at the curved upper part.

Samples Produced by Wiede's Carbidwerk. Four diffusion-treated Verneuil synthetic sapphires were made available by Wiede's Carbidwerk: two samples (green and yellow) from the production of the 1970s, and two samples (blue and green) from recent production. All samples were transparent and showed dual-color double stars (figure 18). Microscopic examination revealed an intense curved growth zoning confined to areas with a variable concentration of gas bubbles (figure 19, left). All four sapphires showed irregular grain boundaries, which were best seen under crossed polarizers (figure 19, right).

Samples Produced by Hrand Djevahirdjian SA. Two samples from recent production of Hrand Dievahirdjian SA (Djeva) were examined for this study. One synthetic ruby, representing the majority of the company's production, was primarily opaque, with only slight translucence at the rim, and showed the normal six-rayed white star of corundum (figure 20, left). The other sample was transparent and revealed a dual-color double-star pattern consisting of a white star confined to the dome of the cabochon and a purplish red second star confined to the base (figure 20, right).

Both samples were grown and heat treated (to form needle-like precipitates) by Djeva in Switzerland and then cut from the rough by Viktor Kämmerling Company (Idar-Oberstein, Germany). In discussions with those involved in the production, it was mentioned that small transparent areas are found on rare occasions close to the tips of the Verneuil-grown ruby boules, near the seed used for crystal growth. The sample depicted in figure 20 (right) was cut from one such transparent area (M.
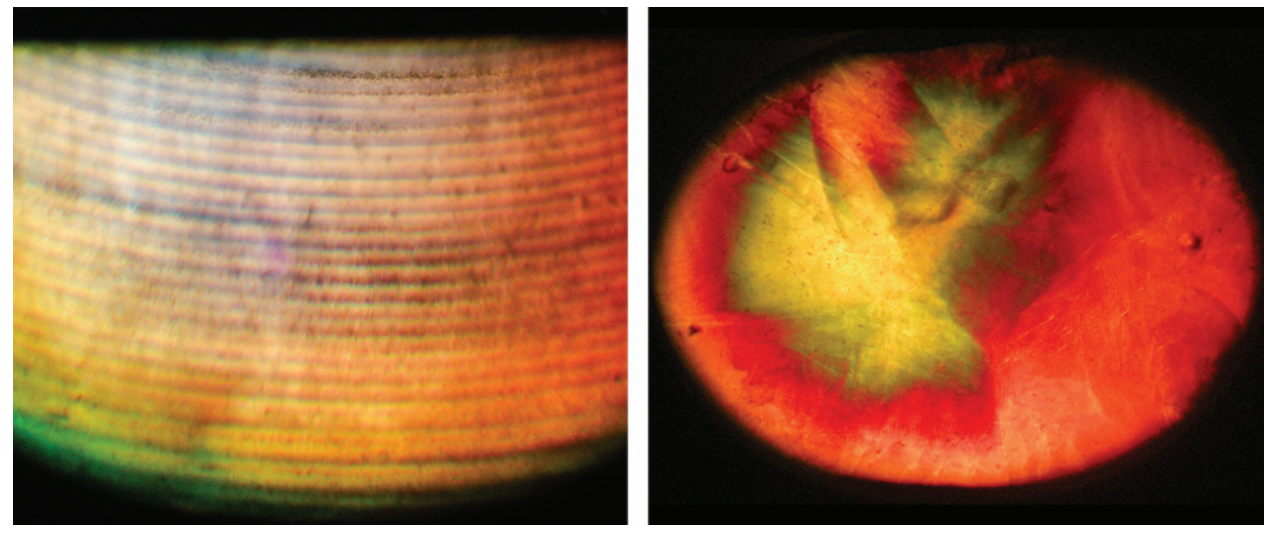

Figure 19. Microscopic features in Verneuil-grown and diffusion-treated sapphires produced by Wiede's Carbidwerk. Left: Curved zones showing different concentrations of gas bubbles. Right: Irregularly shaped grain boundaries. Immersion, crossed polarizers; field of view: $7.6 \times 5.7 \mathrm{~mm}$ (left) and $11.5 \times 8.7 \mathrm{~mm}$ (right). Photos by K. Schmetzer. 

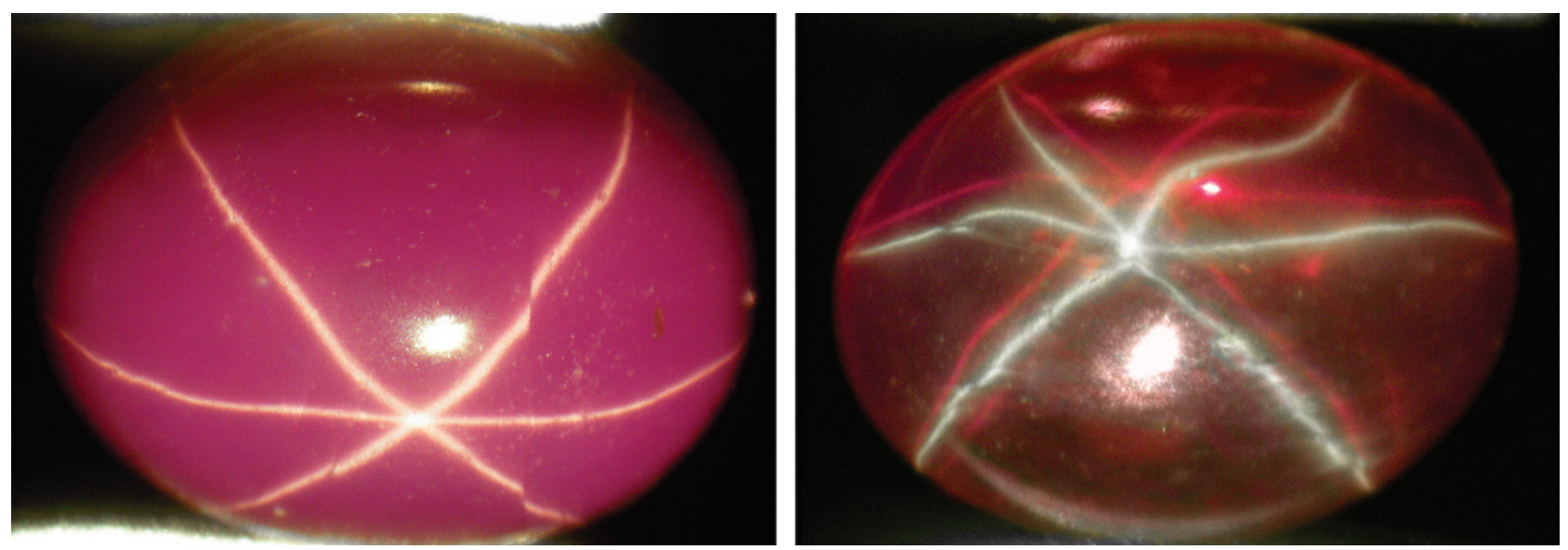

Figure 20. Two synthetic Verneuil-grown rubies from the recent production of Hrand Dievahirdjian SA. The majority of the production consists of opaque material showing an ordinary six-rayed star (left). In a few of the Verneuil boules, a small transparent area is found; when cut as cabochons, these show a double-star pattern consisting of a white and a purplish red star (right). The opaque cabochon measures $9.0 \times 7.0 \mathrm{~mm}$ and weighs $1.95 \mathrm{ct}$; the transparent sample measures $8.8 \times 6.9 \mathrm{~mm}$ and weighs $2.70 \mathrm{ct}$. Photos by K. Schmetzer.

Kämmerling, pers. comm., 2014). According to these discussions, neither the opaque to slightly translucent stone nor the transparent sample was diffusion treated.

Examined in the microscope, the transparent asteriated ruby showing the double-star pattern revealed only inclusions that are typical for Verneuil-grown synthetic rubies (e.g., curved growth striations, irregular grain boundaries, and Plato lines). The only difference seen in the opaque sample was an extremely high concentration of gas bubbles.

Samples Produced by Linde. As previously noted, until the mid-1970s Linde in the United States produced synthetic asteriated corundum in a wide range of colors, and dual-color double stars have been depicted in this material (Arem, 1987; Gübelin and Koivula, 2008). To evaluate the cause and possible mechanism of formation of these Linde double stars, we were able to examine several parcels of Linde synthetic rubies and sapphires kept in various collections in the UK and Germany. In addition, we were able to purchase some samples of "old stock" Linde material (see also box C).

Samples of Linde Synthetics from a 1970s Collection. A collection in the UK of 13 differently colored Linde synthetic sapphires and rubies purchased in the early 1970s was made available for examination (figure 21). The few opaque samples from this collection revealed only the ordinary white six-rayed star, but in translu- cent or transparent samples from this lot, another sixrayed star was apparent (figure 22). This star showed the bodycolor of the corundum host crystal.

Upon microscopic examination, the typical inclusions of Verneuil-grown synthetic rubies and sapphires were observed. The only difference between the opaque, translucent, and transparent samples from this series was a varying concentration of gas bubbles. In other words, samples with a high, layered concentration of gas bubbles were opaque, and samples with a smaller concentration of bubbles were translucent or transparent. These observations indicated that the samples were grown under similar conditions and simply reflected the variations that would be expected to occur during production in the different original boules and/or in different portions of the boules from which they were cut.

To determine if there were specific layers responsible for the formation of the different stars in this group of synthetic corundum cabochons, we were allowed by the owner to grind and repolish the almost plane base of two asteriated cabochons and the dome of a third sample. One or two grinding and repolishing steps were performed, and after each step the samples were reexamined to identify any changes.

After the first step, no distinct change in the appearance of the two differently colored stars was perceptible for any of the three samples. Neither the white star confined to the dome of the third cabochon mentioned above nor the bodycolored star confined to the base of the other two samples was 


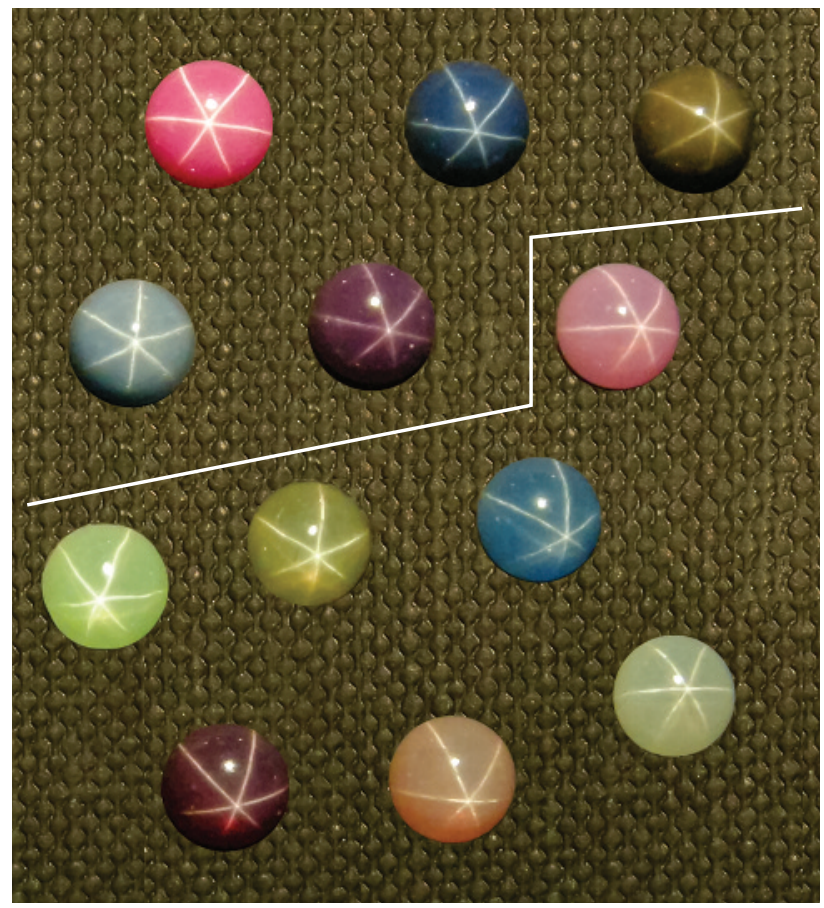

Figure 21. A collection of Linde synthetic rubies and sapphires purchased in the 1970s, each showing a white six-rayed star. The seven cabochons below the line are transparent or translucent and also show a bodycolored star. The samples, which measure 5.0 $5.2 \mathrm{~mm}$ in diameter, have a thickness of 2.5 to 2.7 $\mathrm{mm}$ and weigh 0.63-0.75 ct. Photo by K. Schmetzer; samples courtesy of $A$. Hodgkinson.

removed or altered by the initial grinding and repolishing process (figure 22, left). After a second processing to remove additional thin layers from the bases of the latter two stones and the dome of the third cabochon, the bodycolored star of one pink sapphire became distinctly weaker and was almost removed (figure 22, right). In contrast, the white and bodycolored stars of the other two samples did not show a visible change.

Samples of "Old Stock" Linde Material Purchased in the United States in 2013. Further insight into the historic Linde production was obtained from examining the "old stock" material purchased in the United States in 2013. Two opaque synthetics within this group, one ruby and one blue sapphire, showed only the white star of ordinary asteriated samples and only the microscopic features that are common for such samples.

Two yellow and two light yellowish green synthetic sapphires within this group were transparent and re- vealed the dual-color double-star pattern, with a white star related to the dome of the cabochon and a bodycolored star confined to the base (figure 23).

Microscopic examination showed gas bubbles, irregular grain boundaries, and Plato lines (figure 24). In three samples, a very fine pattern of oriented needles was also observed. The sizes of these needles were at the resolution limit of a normal gemological microscope (up to $100 \times$ magnification).

One yellowish green and one yellow sample from this group were ground and repolished at their bases in two or three different steps. Neither revealed any change in the visual appearance of the stars after two rounds of grinding and repolishing. Finally, a third deeper grinding and repolishing was applied to the base of the yellowish green sample, but again no alteration of asterism was apparent (figure 23).

Figure 22. Left: This light yellowish green sapphire shows $a$ white star and a bodycolored star (top); after grinding and repolishing of the dome, the white star is not removed and both stars are still observed (bottom). The sample measures $5.0 \mathrm{~mm}$ in diameter, with a thickness of $2.4 \mathrm{~mm}$, and weighs $0.58 \mathrm{ct}$ (after grinding and repolishing). Right: This pink sapphire shows $a$ white star and a bodycolored star (top); after grinding and repolishing of the base, the bodycolored star is almost completely removed and only the white star is still observed (bottom). The sample measures 5.1 $\mathrm{mm}$ in diameter, with a thickness of $2.4 \mathrm{~mm}$, and weighs $0.61 \mathrm{ct}$ (after grinding and repolishing). Photos by K. Schmetzer.
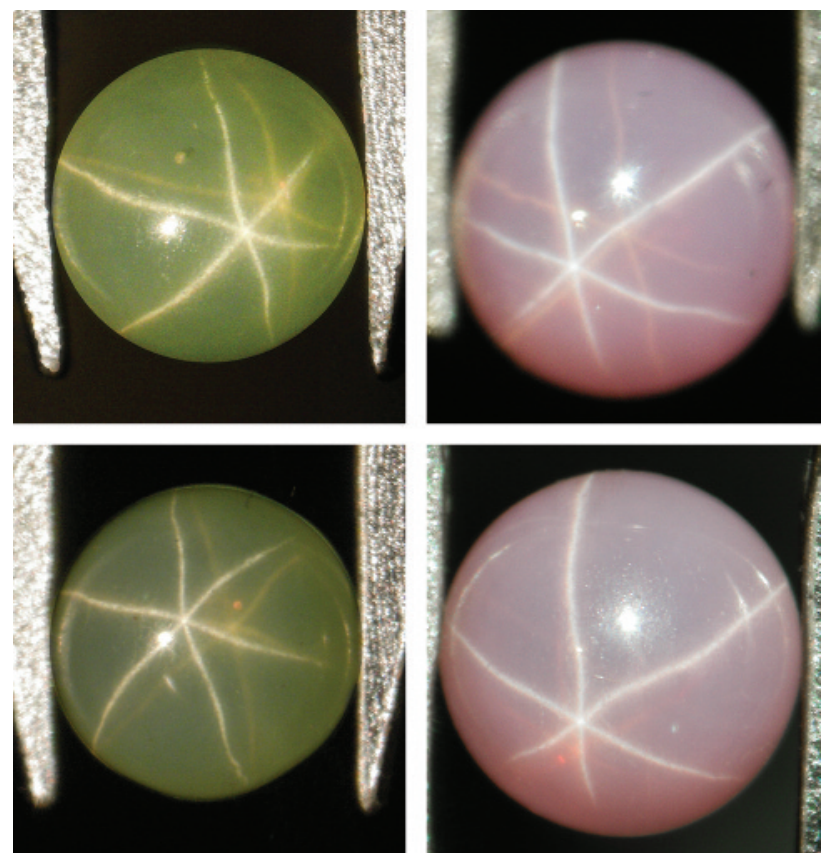

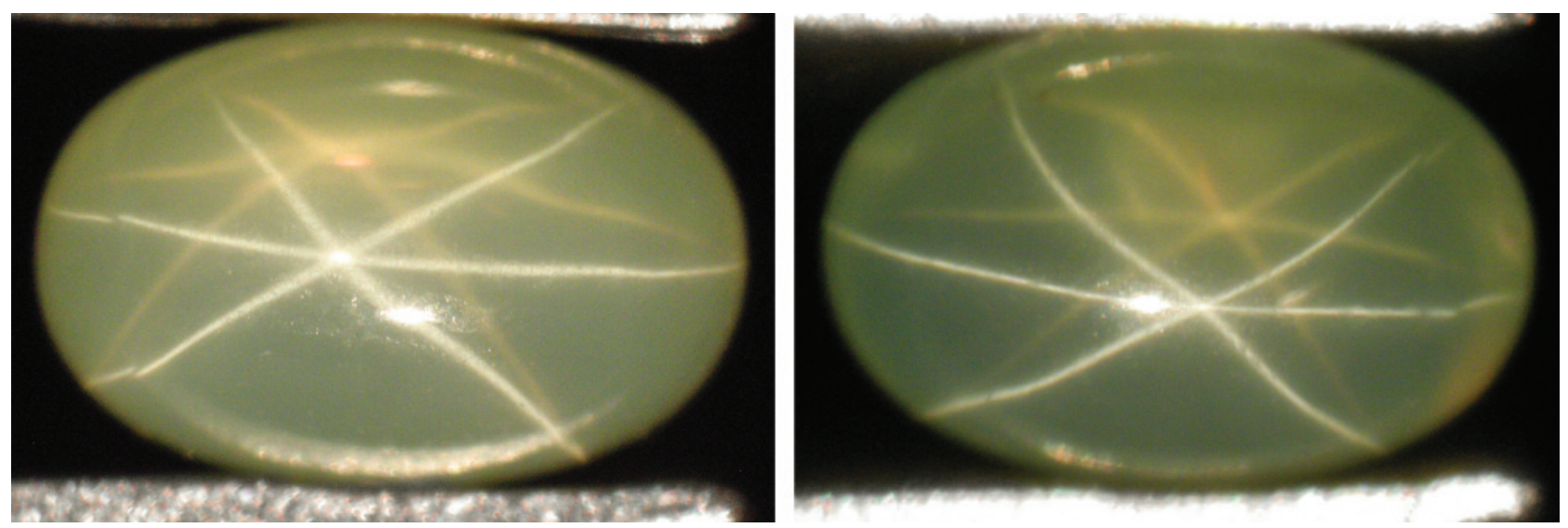

Figure 23. This light yellowish green sapphire shows a white six-rayed star and a bodycolored star (left); after three grinding and repolishing steps at the base of the cabochon, the bodycolored star is not removed and both stars are still observed (right). The sample measures $6.0 \times 4.1 \mathrm{~mm}$, with a thickness of $2.6 \mathrm{~mm}$, and weighs $0.54 \mathrm{ct}$ (after grinding and repolishing). Photos by K. Schmetzer.

As mentioned earlier, within a parcel of approximately 60 partially finished cabochons traced back to a former Union Carbide staff member was a group of samples having inhomogeneous crusts. We examined these crusts to better understand several steps of the production techniques applied by Linde in the late 1960s to the early 1970s, which have not previously been discussed in the gemological literature.

It is unknown if this lot of partially finished, preshaped stones consisted of rejected, in-process, or experimental samples. In general, the crusts covered only part of the surface of the cabochons (figure 25).

Figure 24. Irregularly shaped grain boundaries within a Verneuil-grown synthetic sapphire produced by Union Carbide under the Linde trade name. Immersion, crossed polarizers, field of view $2.4 \times 1.8 \mathrm{~mm}$. Photo by K. Schmetzer.

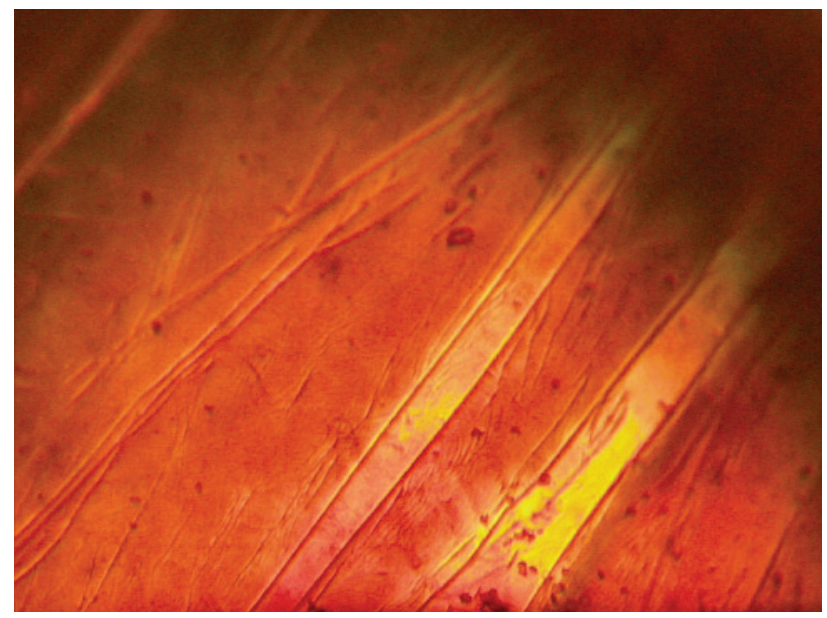

As previously detailed, the crusts on the surface of seven samples (red, purple, and green) were characterized by X-ray fluorescence, and five of these samples were also examined by micron-scale X-ray fluorescence mapping.

To recapitulate the results, it was found that the crusts, in most cases, consisted primarily of ironbearing solids, occasionally associated with other trace elements, but no titanium was found as a major component. Thus, we concluded that the crustal elements were applied for diffusion to enhance the appearance, mainly color, of the samples, but not for improvement and/or creation of asterism. However, as already mentioned, it is unknown if these samples represented part of the commercial production or were simply test samples to investigate the possibility of color improvement.

Needles in Synthetic Rubies and Sapphires at Higher Magnification. Two cabochons of sample types proven to be diffusion-treated by the grinding and repolishing experiments and two cabochons that showed no alteration after such experiments were examined at higher magnification (up to 1000x) in reflected and transmitted light. In all four samples, elongated thin needles of similar visual appearance, most likely rutile needles, were observed (figure 26). Views toward the dome and toward the base of the cabochons revealed no perceptible difference in the appearance of the needles. The needles were up to 50 $\mu \mathrm{m}$ long, and their thickness ranged from 0.3 to 0.4 $\mu \mathrm{m}$. Knee-shaped twins and V-shaped twins were seen occasionally. 

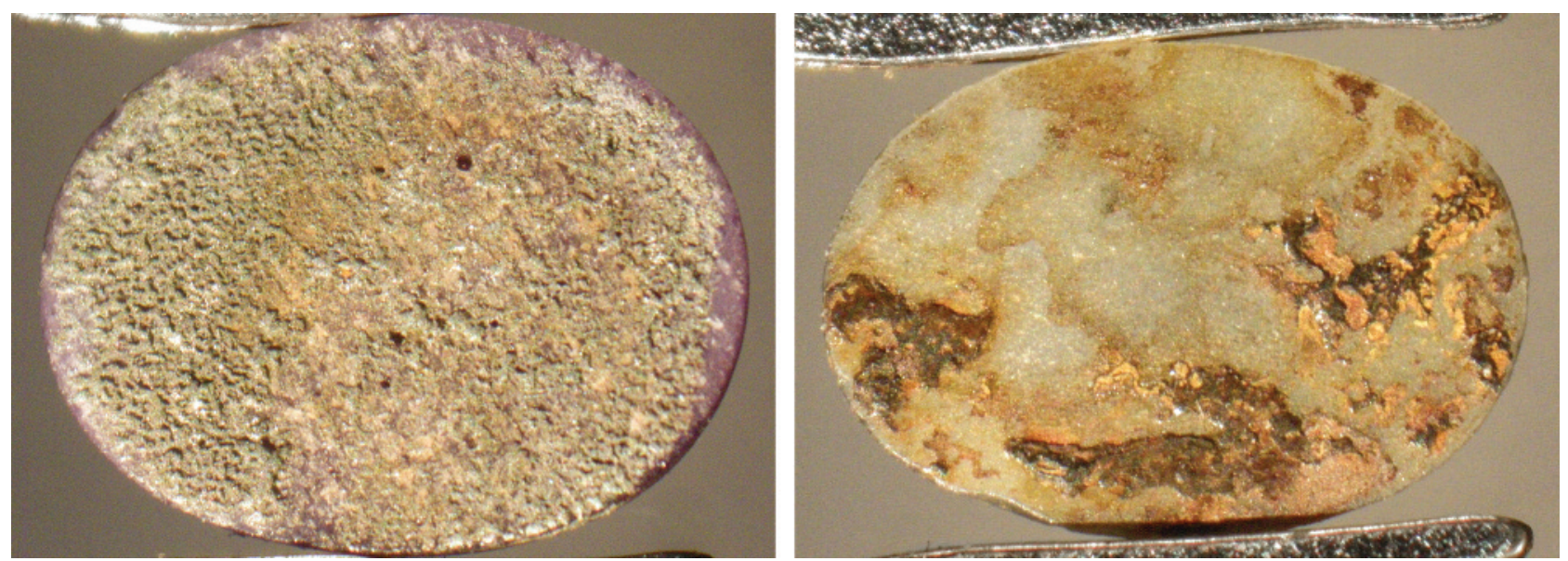

Figure 25. Inhomogeneous crusts of iron-bearing compounds on the base of a pre-shaped purple sapphire (left) and the base of a grayish green sapphire cabochon (right) from Linde. These samples may reflect diffusion treatment involving materials other than titanium, at least on an experimental basis, for enhancement of color in asteriated ruby and sapphire. The purple sample measures $8.3 \times 6.4 \mathrm{~mm}$, and the grayish green sample measures $7.1 \times 5.1$ mm. Photos by K. Schmetzer.

Quartz from Brazil and India. During the course of this project, asteriated natural quartz samples from two sources were made available. (At present, synthetic asteriated quartz is unknown.) We were able to examine two almost colorless, very slightly pink rose quartz cabochons from Brazil, inspired in partic- ular by the observations of Killingback (2006, 2011) on a transparent rose quartz sphere, and two slightly brownish pink quartz cabochons from India. Numerous localities in Brazil have been mentioned as sources for asteriated rose quartz (Cassedanne and Roditi, 1991), but the exact source for the samples
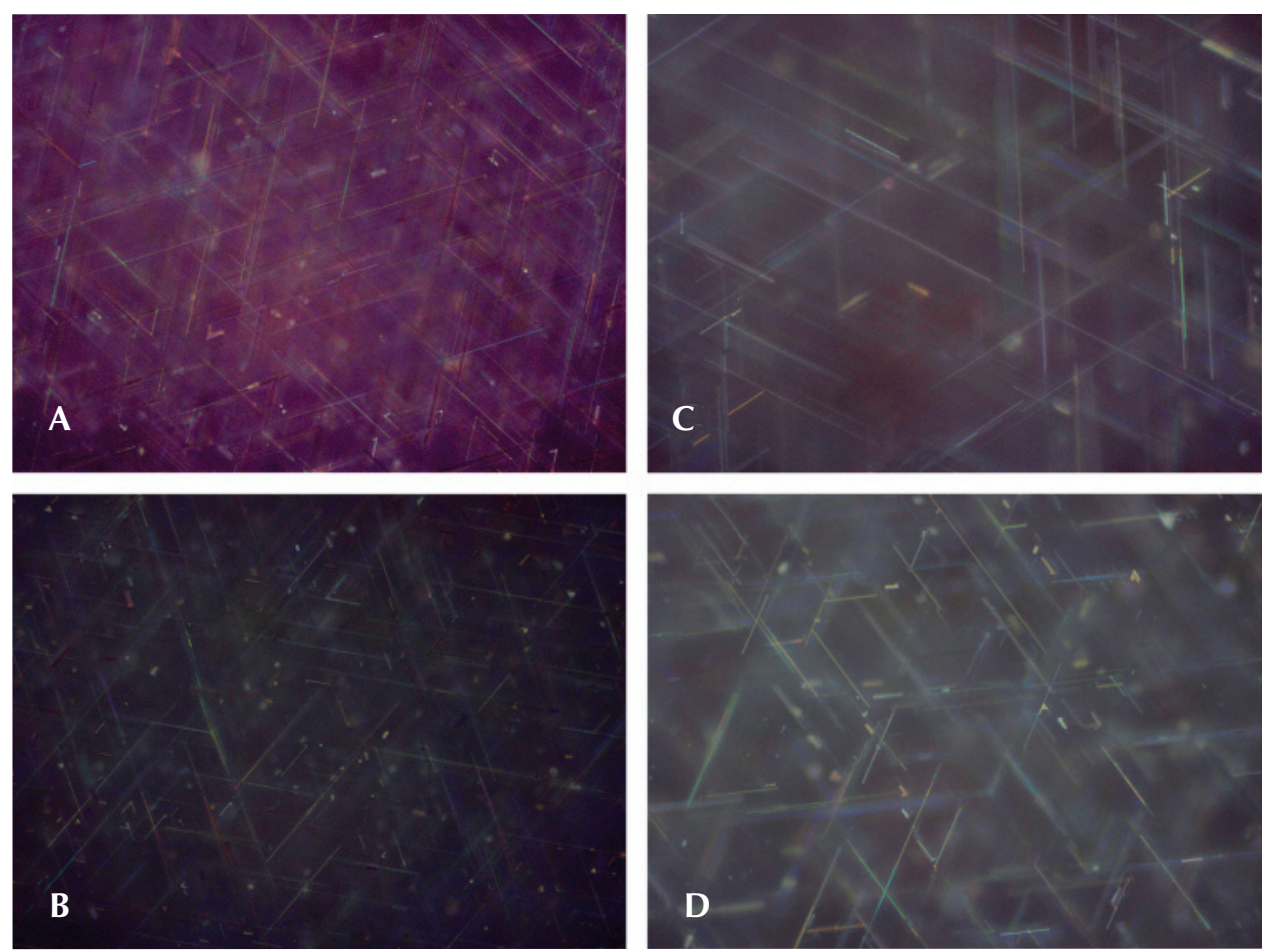

Figure 26. Rutile needles in four corundum samples with double stars, as observed in a view toward the curved dome. A: Purplish ruby from a collection of Linde samples from the 1970s (see figure 21, lower left); B: Light yellowish green sapphire of "old stock" Linde material (see figure 23); C: Diffusion-treated ruby sold under the "Linde" trade name but traced back to the Asian market (see figure 15, left); $D$ : Diffusion-treated yellow sapphire purchased in 2010 in Bangkok (see figure 10). Reflected light, oil immersion; field of view $92 \times 69 \mu \mathrm{m}$. Photos by H.-J. Bernhardt. 


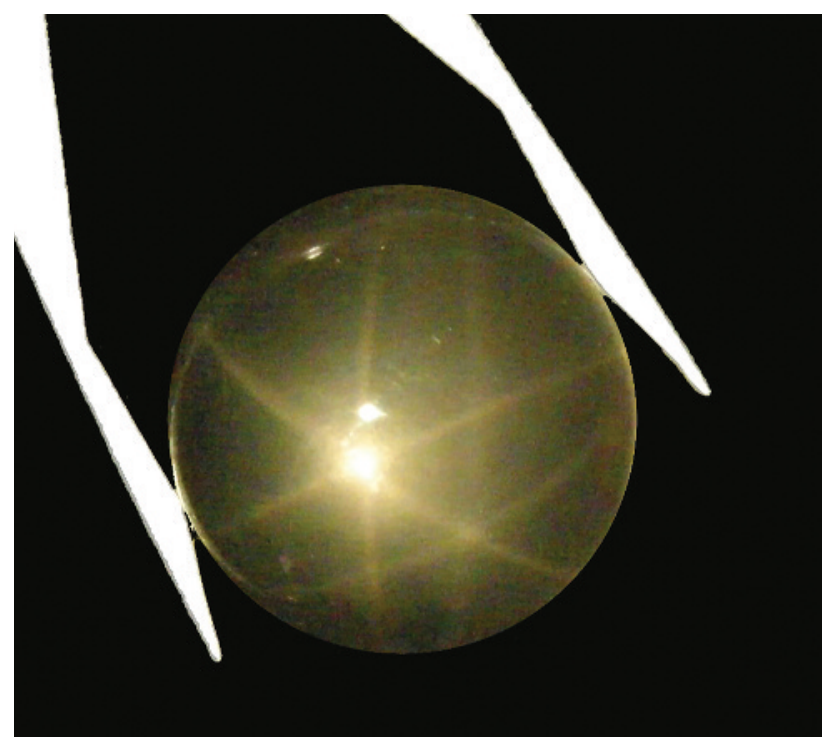

Figure 27. Very light rose quartz cabochon from Brazil showing double stars in reflected light. The cabochon measures $21.0 \mathrm{~mm}$ in diameter and weighs $26.18 \mathrm{ct}$. Photo by K. Schmetzer.

examined is unknown. In India, asteriated rose quartz is known from the Kekri region, in the Tonk district of Rajasthan (G. Choudhary, pers. comm., 2014). This might be the source for the two cabochons studied as part of the present research project.

Rose Quartz from Brazil. In reflected light, both Brazilian samples showed a six-rayed dual-color double-star pattern, closely resembling the pattern in very light-colored sapphires (figure 27). Again, the star related to the curved dome of the cabochons was white, but the color of the other star related to the plane base was slightly pink.

During the examination, it became apparent that asterism in transmitted light (diasterism), which produced a single star, was much stronger than asterism in reflected light (epiasterism), which produced the double-star pattern.

In the gemological microscope, no individual needles or elongated particles were resolved with the magnification permitted.

Brownish Pink Quartz from India. Compared to the color of the cabochons available from Brazil (see above), the Indian samples had a light "smoky" color component in addition to the ordinary pink that is typically seen in rose quartz.

When offered in the trade, such material is frequently sold with a rough (unpolished) base to enhance the visual appearance of the white six-rayed star. With this type of cabochon, a second star is gen- erally not observed. After polishing the base of the two samples studied here, however, the presence of a second star confined to the base was clearly visible (figure 28). The light bands exhibited by the brownish pink material from India were less sharp than those seen in the rose quartz samples described above.

Examination with the gemological microscope again did not indicate any needle-like inclusions resolved with the magnification of the instrument.

Needles in Quartz from Both Sources at Higher Magnification. The Brazilian rose quartz and Indian quartz cabochons were examined at higher magnification (up to 1000x) in reflected and transmitted light. In all four samples, elongated thin needles were observed.

In the rose quartz cabochons from Brazil, some of these needles were oriented in three directions approximately perpendicular to the c-axis (i.e., in the basal plane), but other orientations inclined to this plane were also observed frequently (figure 29, A and B). An analysis of some of these needles by micro-Raman spectroscopy identified them as the mineral dumortierite (figure 29C). Previous studies involving dissolution of the host and examination of the residual fibers have established dumortierite as an inclusion in rose quartz from various localities (Applin and Hicks, 1987; Goreva et al., 2001; Ma et al., 2002). In the present case, we were able to identify some of the larger needles within the host by non-destructive means.

Notably, in both cabochons from Brazil, the network of needles oriented in the basal plane and visi-

Figure 28. Slightly brownish pink quartz cabochon from India showing a double star in reflected light. The cabochon measures $24.2 \times 18.8 \mathrm{~mm}$ and weighs 50.30 ct. Photo by K. Schmetzer.

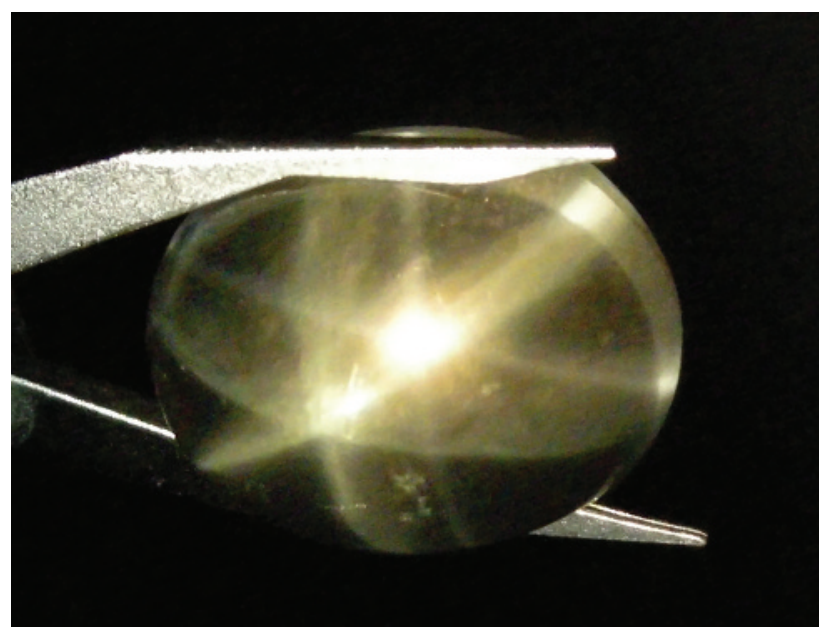



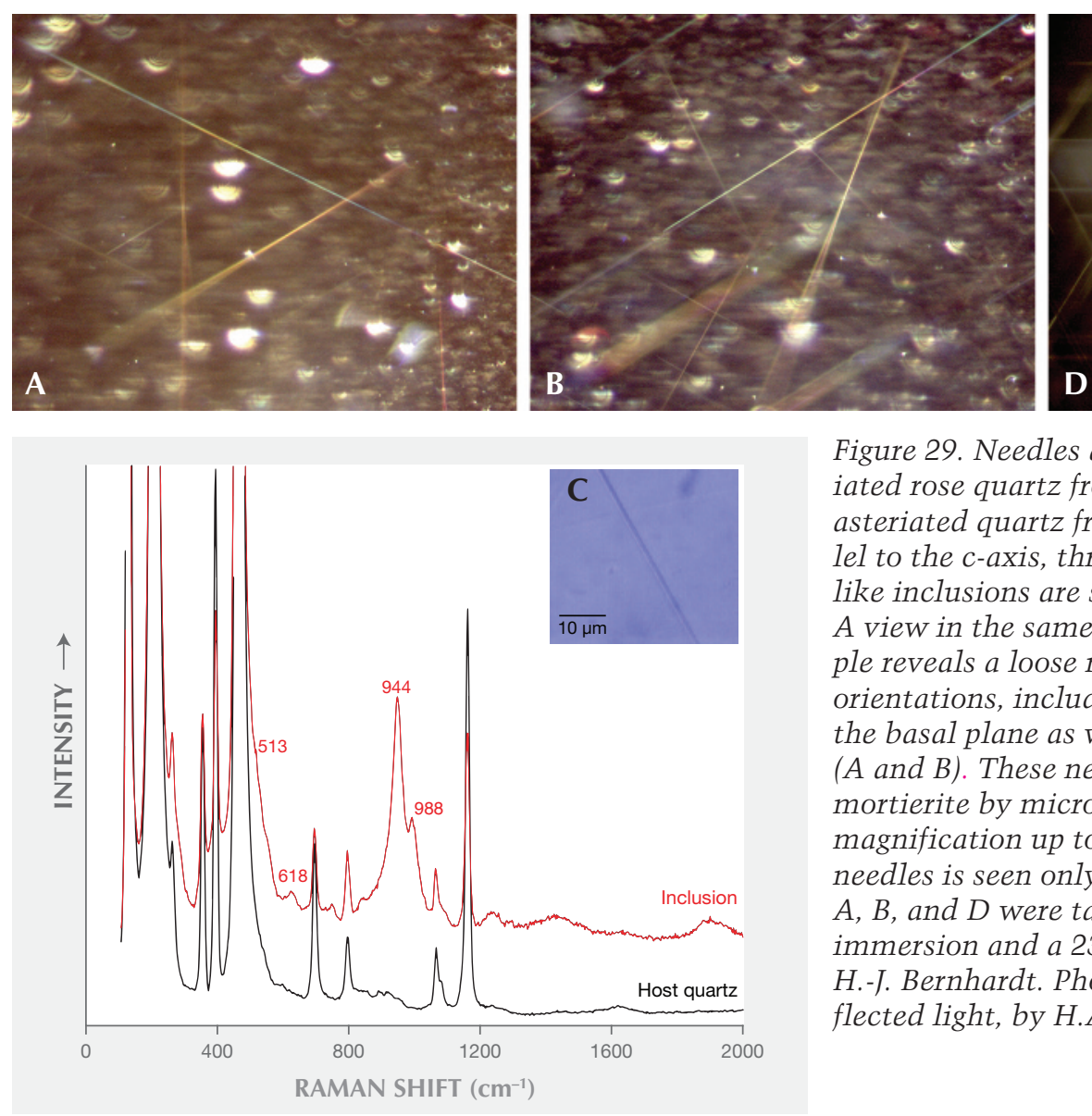

Figure 29. Needles and spectroscopic data in asteriated rose quartz from Brazil (A, B, and $C$ ) and in asteriated quartz from India $(D)$. In a view parallel to the c-axis, three series of intersecting needlelike inclusions are seen in the sample from India. $A$ view in the same direction of the Brazilian sample reveals a loose network of needles in various orientations, including both generally parallel to the basal plane as well as inclined to that plane (A and B). These needles were identified as dumortierite by micro-Raman spectroscopy (C). At magnification up to 1000x, a dense network of needles is seen only in the Indian samples. Photos $A, B$, and $D$ were taken in reflected light, with oil immersion and $a 230 \times 150 \mu \mathrm{m}$ field of view, by H.-J. Bernhardt. Photo C (inset) was taken in reflected light, by H.A. Gilg. ble at higher magnification was not dense. This fact and the presence of similar needles inclined to the basal plane indicated that these needles were not responsible, at least not alone, for the asterism of the samples. Most likely, an additional denser network of smaller needles is also present.

In contrast to the Brazilian rose quartz just discussed, the samples from India featured a dense network of oriented needle-like inclusions in the basal plane, and only a few single needles were seen with an orientation oblique to that plane (figure 29D). An examination of some of these elongated inclusions by micro-Raman spectroscopy did not unequivocally identify the mineral or substance responsible. Nonetheless, it was evident that the appearance of needle-like inclusions differed in the samples from the two sources.

Although rutile needles are common inclusions in quartz, other needle-like inclusions (e.g., sillimanite or ilmenite) have also been identified in asteriated samples. Thus, without further examination, such as by electron microscopy and electron diffraction (given the small diameter of the needles), an attempt to offer a specific identification for the needles causing asterism in the rose quartz from Brazil and in the brownish pink quartz from India would be speculative.

\section{DISCUSSION}

Microscopic Features. The Verneuil-grown synthetic rubies and sapphires did not exhibit any atypical microscopic features. Most samples revealed irregular grain boundaries, and several showed prismatic glide planes (Plato lines). Curved growth striations were typically seen in rubies, while the blue sapphires frequently showed curved layers with different concentrations of gas bubbles. Occasionally, gas bubbles were also seen in areas not related to growth features. The size of the rutile needles, in general, was near or below the resolution limit of the gemological microscope, but three series of needles could be clearly observed at higher magnification.

The main difference between the transparent or translucent samples showing the dual-color doublestar pattern and the non-transparent samples without a double-star pattern was the concentration of gas bubbles. 

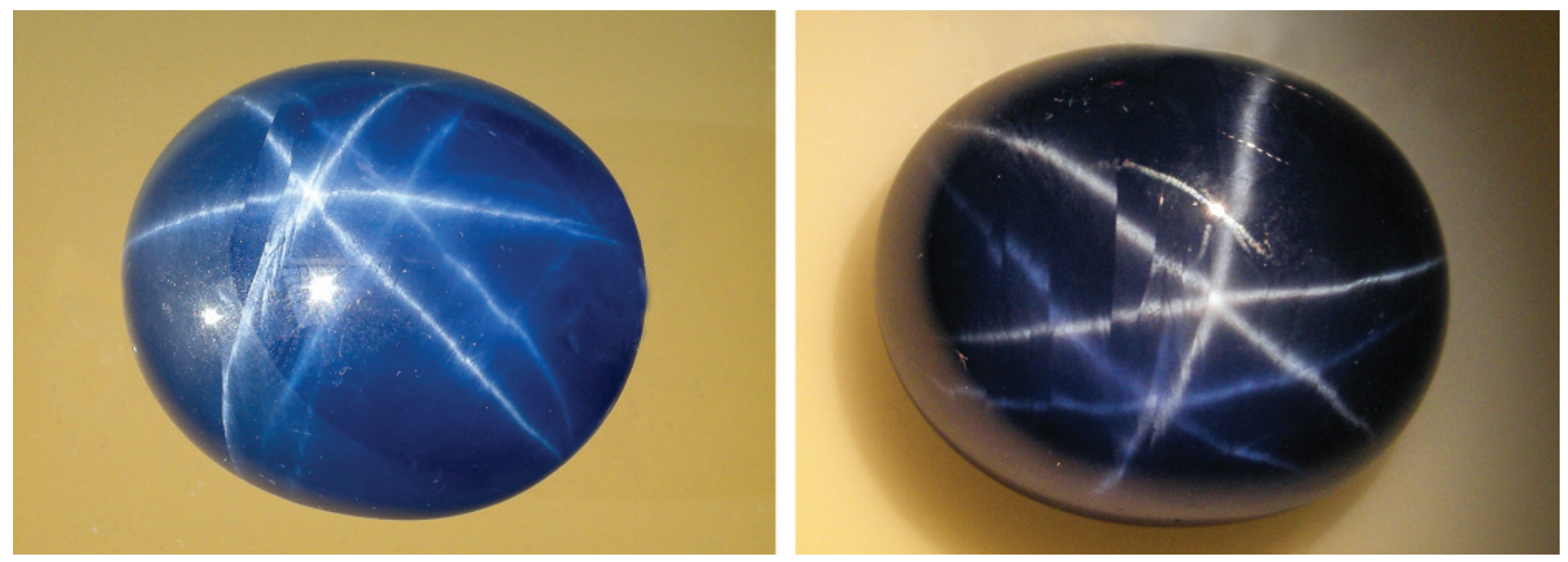

Figure 30. Large diffusion-treated sapphire grown by the Verneuil method. The sample reveals, due its high transparency, a typical double-star pattern. The photos show the different visual appearance of the sample in direct sunlight (left) and under fiber-optic illumination (right). The arms of the stars are cut by grain boundaries, which indicates that parts of the crystal have slightly different orientation. The cabochon measures $27.7 \times 23.5 \mathrm{~mm}$ and weighs $91.41 \mathrm{ct}$. Photos by K. Schmetzer.

In the natural sapphire, the oriented needles were distinctly larger, especially in thickness. Their concentration varied in different parts of the stone and also tended to be higher along prismatic and dipyramidal growth planes. The sample was determined to be a single crystal, a property that caused the arms of the two six-rayed stars to be parallel. In twinned corundum crystals, the two stars are inclined to each other, and both stars show an identical white coloration. Dual-color double stars in natural rubies and sapphires are rare because most asteriated samples are neither transparent nor translucent, and therefore a reflection of light from the base cannot be seen.

In the asteriated brownish pink quartz samples from India, a dense network consisting of three series of oriented needle-like inclusions was observed. In the rose quartz from Brazil, only a very low density of needles, identified as dumortierite, was seen in an orientation parallel to the basal plane, and other needles inclined to this plane were also present. It could not be assumed that the relatively few needles visible in the basal plane were responsible for the observed asterism. Rather, there likely exists a denser network of smaller needles (not resolved with the magnification applied) generating the asterism in these rose quartz samples, but this topic needs further research.

Formation of Dual-Color Double Stars in Rubies, Sapphires, and Quartz. The dual-color double stars that are the subject of this study consist of a white six-rayed star and a bodycolored six-rayed star, a phenomenon different from the double stars of identical coloration that are sometimes observed in twinned rubies and sapphires. The two stars studied here are superimposed, overlapping each other, when the incident light is directed to the center of the cabochon and the observer looks parallel to this path of light. The two stars are clearly separated, however, if the observer and the incident beam of light are not parallel, which can be accomplished by shifting the observer, the incident light, or the cabochon.

For the observation of dual-color double stars, the surface at both the dome and the base of the cabochon needs some polish, but not necessarily a highquality polish. Our experiments demonstrated this requirement. In certain samples (e.g., in some quartz cabochons), a bodycolored star was not seen when the base was completely rough. In these samples, the star became visible after polishing the surface. Similarly, some cabochons with extremely poor polish at the base showed only a very diffuse bodycolored star.

An analogous double-star pattern was also seen in reflected light for samples with two curved surfaces, irrespective of which curved surface layer the incident light was directed toward (again, see figure 6). Moreover, the size of the cabochon did not appear to be a factor in the ability to present a dual-color double-star pattern, provided the transparency was sufficient (figure 30).

The dual-color double stars described in this paper are observed in two basic groups of natural and synthetic corundum and natural quartz. One group consists of transparent to highly translucent natural or synthetic corundum and natural quartz with needlelike inclusions distributed throughout the entire body of the cabochon. A second group consists of dif- 


\section{Box B: InSIGHt into Production TeChNiques ApPLIED fOR THE FORMATION AND IMPROVEMENT OF ASTERIATED CORUNDUM SinCE THE LATE 1960s}

During the course of this study, the authors communicated with individuals involved in the early production and marketing of asteriated synthetic corundum, shedding new light on its largely hidden past. The information summarized below comes from two main sources: the family that operates Wiede's Carbidwerk, and several former employees of Union Carbide (Linde). The summaries focus on aspects related to gemology and general production techniques for the materials released to the market. Details of production such as heating temperatures and times and the exact composition of nutrients and gases are outside the scope of the present paper.

\section{Insight from Wiede's Carbidwerk}

One of the authors (KS) was able to speak with $\mathrm{H}$. Schulz and his father C. Schulz, who have been directing Wiede's Carbidwerk in Freyung, Germany, since the late 1960s. Verneuil-grown and diffusion-treated star sapphires from recent production of the company and from the production of the 1970s were described earlier. From these interviews, we learned that diffusion treatment is applied to improve the intensity of weak stars, especially in transparent or translucent materials of certain colors. Furthermore, an uneven distribution of the star in various parts of the stone, sometimes associated with color zoning, can be improved by diffusion. Some trace elements used as dopants can cause complications if they are added in the nutrient for crystal growth together with titanium. This leads to the problem in which samples with asterism and specific colors such as bright green or bright yellow cannot be produced in one single step by the Verneuil technique. Instead, asteriated synthetic sapphires of such colors can be produced by adding the specific dopant for the desired color (e.g., cobalt for bright green or nickel for bright yellow) to the nutrient for Verneuil growth of the sapphires, then adding titanium by diffusion to the surface of the samples in a second step, and finally producing rutile precipitates by subsequent heat treatment.

The reverse process of adding titanium to the nutrient and then diffusing a color-causing trace element in a subsequent step is also a possible method for achieving asteriated sapphires of the desired coloration. Since the 1970s, however, Wiede's Carbidwerk has principally utilized the first variant described for commercial production, including for the samples supplied for this paper.

The existence of a bodycolored second star has been known to the producers at Wiede's for decades. Their experience has been that some clients want stones with this specific pattern, while others ask that the bodycolored second star be removed (e.g., by a slight grinding and repolishing of the cabochon's base).

\section{Insight from Former Linde Employees}

Jennifer Stone-Sundberg, an employee of the former Union Carbide crystal growth facility from 2002 to 2008, and Milan Kokta, who worked at Union Carbide from 1977 to 2007 and devoted part of his research to improving the lasing properties of titanium-bearing synthetic sapphire (see the patents by Kokta in the references list), located some of the former staff members at Linde to obtain firsthand information. The following summary is based on interviews with Tony Keig, Milan Kokta, Larry Rothrock, Jim Smith, and one individual who wishes to remain anonymous:

From 1966 to 1968, the Linde subsidiary of Union Carbide produced red, white, blue, and black star material, with approximately $80 \%$ of the production blue, fusion-treated rubies and sapphires in which precipitates of rutile needles are restricted to thin layers at the dome and base of the samples. The white star is formed by reflection and scattering of light at the needle-bearing surface layer confined to the dome of the cabochons; the bodycolored star is formed by reflection and scattering of light at the needle-bearing surface layer confined to the base. If either surface layer is free of needle-like inclusions, the related star is not seen.

Grinding and repolishing the first group of samples will not change the visual impression of the double stars, because the surface-related layers still contain acicular inclusions. Conversely, the white stars as well as the bodycolored stars of the second group can be removed by simple grinding and repolishing of the curved dome or the planar base. For some samples, especially synthetic rubies and sapphires purchased recently in Asia, the stars were removed completely after one or two grinding and repolishing steps. These results proved diffusion treatment of the samples to create asterism. 
$15 \%$ red, close to $5 \%$ black, and a very small fraction of $1 \%$ white. Linde expanded beyond blue, red, white, and black in the very late 1960s to produce the birthstone colors, the motivation behind all of the offerings outside of red and blue.

Verneuil raw materials did contain titanium, but many of the other metals for colors could not be successfully incorporated in the growth process and had to be added via post-growth diffusion. Specifically, attempts at incorporating an amount of dopant higher than that needed for some technical applications such as laser purposes, and necessary to produce satisfactory color in combination with asterism in gem materials, led to a rapid reduction in crystal quality. Therefore, Union Carbide experimented with diffusion to enhance or create a variety of colors in asteriated material.

These experiments proved effective, and post-growth diffusion was employed commercially for coloration purposes, either with or separate from the heat treatment needed to bring out the star. Some amount of titanium was always incorporated into the melt, and the crystal was then oxidized to bring out the star. If a different bodycolor was desired, the metals for that would be diffused in post-growth processing. Additionally, postgrowth diffusion of titanium in flame-fusion material was utilized if the star obtained after growth and heat treatment was not sufficiently strong.

Later, the company changed the focus of its crystal growth efforts exclusively to the Czochralski technique. This method proved undesirable for the commercial production of asteriated synthetic gems, but it was used for some time in the 1980 s to produce non-phenomenal ruby, blue sapphire, and green garnet synthetic gem material. However, Czochralski-grown materials for jewelry purposes did not reach the market in large quantities as had the Verneuil-grown Linde star material in the decades before. In the mid-1970s, with the shift toward Czochralski growth of corundum and a similar shift toward technical applications such as solid-state laser crystals, the company completely ceased production and marketing of Verneuil-grown star sapphire. The equipment (burners) was sold to third parties outside of the company, and the patents dealing with diffusion of various color-causing trace elements were transferred to Astrid Corporation (see table A-1).

The information from the directors of Wiede's Carbidwerk and from former employees of Union Carbide is thus consistent with the results presented in this paper. Their comments corroborate a variety of aspects regarding diffusion and asterism that were demonstrated empirically in the samples studied. These aspects include: (1) production of asteriated materials through the use of a titanium dopant in the growth process and through post-growth diffusion; (2) use of diffusion to create asterism and to enhance weak or incomplete stars; and (3) a need for technical reasons in certain color varieties to add titanium and the coloring element separately. On this latter point, it is also noteworthy that the patent documents by Carr and Nisevich (first application of this series filed in the United States on December 20, 1971, published 1973 to 1977; see table A-1) mention diffusion of the following elements or combinations of elements along with titanium into the corundum lattice: iron, chromium, vanadium, cobalt, nickel, and magnesium. However, the specific examples given of the colors produced by the diffusion process are limited (e.g., gray-green after diffusion of nickel, or pink after diffusion of chromium).
In transparent or translucent materials produced by the Linde subsidiary of Union Carbide and distributed as "Linde stars," testing was somewhat limited. Nonetheless, grinding and repolishing led to a distinct decrease in the intensity of the bodycolored star for a pink synthetic sapphire. This result established that the cabochon had undergone diffusion to create or improve its asterism. Other samples loaned from various collections could not be ground and repolished or handled destructively (e.g., cut in slices). Consequently, for part of the samples it was not possible by non-destructive analyses to decide whether tiny rutile needles were present within the entire sample or confined to the layers at the outer surfaces.

For the yellow or yellowish green "old stock" Linde samples we purchased, asterism was not changed after grinding and repolishing. Thus, experimentation did not offer any direct proof of diffusion treatment for these samples but did strongly suggest use of a titanium oxide raw material in the original crystal growth charge. 
Microscopy of the yellow and yellowish green samples showed the presence of needle-like precipitates in the outermost layers of the cabochons. No changes were observed in these samples, even after deeper grinding and repolishing steps, which would have removed, at least partly, an existing diffusion layer. This fact indicates that rutile precipitates permeated the body of these synthetic sapphires. The distribution of rutile needles throughout the cabochons was also established for a transparent sample cut from a ruby boule grown by Dieva in Switzerland and a natural sapphire from Myanmar.

Accordingly, through comparison of commonalities between the treated and untreated corundum samples, the following mechanisms can be applied to explain the phenomenon in both groups:

1. The ordinary white star is formed by reflection and scattering of light at a layer confined to the curved dome of the cabochon and consisting of a matrix of corundum and minute needle-like precipitates of a titanium-bearing substance (rutile needles).

2. The bodycolored second star is formed by reflection and scattering of light at a layer confined to the plane or slightly curved base of the cabochon and consisting of a matrix of corundum and minute needle-like precipitates of a titanium-bearing substance (rutile needles).

3 . The light forming the second star travels twice through the body of the cabochon and is absorbed by trace elements such as vanadium, chromium, iron, nickel, or cobalt, which are responsible for the bodycolor of the corundum crystals. Thus, the color of the second star is identical to the bodycolor of the host corundum.

The observations described for quartz cabochons clearly indicate the following mechanisms for the formation of the dual-color double-star pattern in transparent, very light-colored samples that is quite similar to the mechanism of such double star formation in transparent corundum. In particular:

1. The ordinary white star is formed by reflection and scattering of light at the curved dome of the cabochon.

2. The slightly pink, almost colorless second star is formed by reflection and scattering of light at the plane or slightly curved base of the cabochon.
3. The light forming the second star travels twice through the body of the cabochon and is absorbed by the color-causing substances that are responsible for the pink coloration of the quartz. In very light, almost colorless host crystals, the second six-rayed star is likewise only very slightly colored, almost colorless.

In both corundum and quartz, the formation of dual-color double stars depends on the presence of three series of acicular inclusions. These inclusions are inclined to each other but located on basal planes perpendicular to the optic axis of the samples.

\section{Implications Regarding the Production of Synthetic} Asteriated Corundum and the Role of Diffusion. The empirical results and interpretations described in the preceding sections led to conclusions regarding the production of asteriated synthetic corundum, particularly the prominent but largely unexplored role of diffusion. To date, diffusion treatment has been discussed in gemological contexts primarily for enhancement of natural colors in rubies and sapphires and for development or improvement of asterism in natural stones. Although there has been some knowledge of the different "Linde" patents (see table A-1), the same cannot be said for the broader commercial application of diffusion treatment processes to synthetic materials since the 1970s.

Rather, it would appear that those involved in the trade in the 1970s and 1980s were unaware of these applications or assumed that they were not used commercially on a large scale (Nassau, 1981; Crowningshield and Nassau, 1981; Hughes, 1991, 1997). Therefore, some insight into production techniques was sought directly from those involved, through interviews as detailed in box B. An application of this information combined with the results of the present study is given in box C.

The remarks of the producers and the empirical results of the present study intersected in establishing that many diffusion techniques were used historically and are still applied to produce the various types of dual-color double stars in synthetic rubies and sapphires seen on the market today. Moreover, the prevalence of the treated stones may depend in part on individual dealer preferences, which can dictate whether the synthetic rubies and sapphires are sold with the phenomenon or ground and repolished to remove the bodycolored stars. However, it should be noted that the particular technique of diffusing both 
titanium and another color-causing dopant was not observed among the samples examined in this paper. An example of such material, with an enrichment of titanium and chromium by diffusion or overgrowth in the outermost layers of an orange-red ruby, was recently described by Schmetzer and Hainschwang (2012).

A detailed discussion of known and possible use of diffusion processes for the enhancement or creation of stars and for improvement of color in natural corundum samples, including through application of these techniques available since at least the early 1970s, is likewise beyond the scope of the present paper. Moreover, the results of this study suggest that detecting the diffusion of titanium (with or without an additional colorant) into natural stones to intensify their stars, regardless of any additional change to the stone's bodycolor, may constitute one of the greater challenges for the gemological community.

\section{CONCLUSIONS}

The examination of various types of natural and synthetic rubies, sapphires, and quartz showing dual-color double stars as an optical phenomenon sheds light on understanding this pattern as well as on the production techniques for asteriated corundum from the 1950s to the present day. In order to produce synthetic asteriated rubies and sapphires of desired color and with intense stars, Verneuil-grown samples were often diffusion treated to create or enhance the cabochon's bodycolor, its asterism, or both. The formation of dual-color double stars is related to needle-like inclusions or rutile precipitates in the outermost layers of synthetic corundum cabochons or to similar acicular inclusions distributed throughout the entire body of natural or synthetic corundum or natural quartz. Reflection and scattering involving the inclusions near the dome creates the white star commonly seen, while reflection and scattering involving the inclusions at or near the base produces the bodycolored second star.

\section{Box C: Application of Results to Two Historical Samples}

Two synthetic sapphire samples produced by Linde and exhibiting interesting features are kept in the reference and teaching collection of the Gemmological Association of Great Britain (Gem-A) in London. An opportunity to examine these samples afforded a chance to apply the results of our investigations as detailed above to propose an explanation for the stones' genesis.

Visual Appearance and Microscopic Examination One sample was a transparent synthetic sapphire cabochon that showed an extremely uneven color distribution, with a primarily colorless core and a blue rim. A six-rayed star was confined only to the blue areas of the sample (figure C-1). A similar blue synthetic sapphire with an incomplete star has already been described in the literature (Koivula and Kammerling, 1991), and a ruby showing this phenomenon was mentioned in Fryer et al. (1982a).

Upon microscopic examination, it was observed that gas bubbles were present only within the blue layers of the sample and that the concentration of the bubbles differed between these layers. In detail, the observed pattern was a mixture of the three basic patterns depicted in figure A-6. Similar blue Linde non-asteriated synthetic sapphire cabochons with uneven color distribution have been encountered by one of the authors (KS) in various collections, and one such example is shown in figure A-1.

The second Linde sample was a completely transparent, color-zoned blue synthetic sapphire. The blue coloration was concentrated toward the rim of the sample, but a six-rayed star extended over the entire cabochon. The stone showed a high concentration of gas bubbles only in some of the outermost parts of the sample (figure C-2). This synthetic sapphire also exhibited a six-rayed second star confined to the base of the cabochon.

\section{Possible Growth Conditions}

Unfortunately, it is not documented when these two synthetic sapphires became part of the Gem-A teaching and reference collection (L. Gleave, pers. comm., 2013). Nonetheless, the descriptions of the manufacturing processes in patent documents (see box A) and the results of the present study indicated that both Linde samples were grown at an early stage of production.

As described by Burdick and Jones (1954a) in the patent assigned to Union Carbide (Linde), complete stars extending over the entire curved domes of the cabochons were created by growing the synthetic corundum boules 

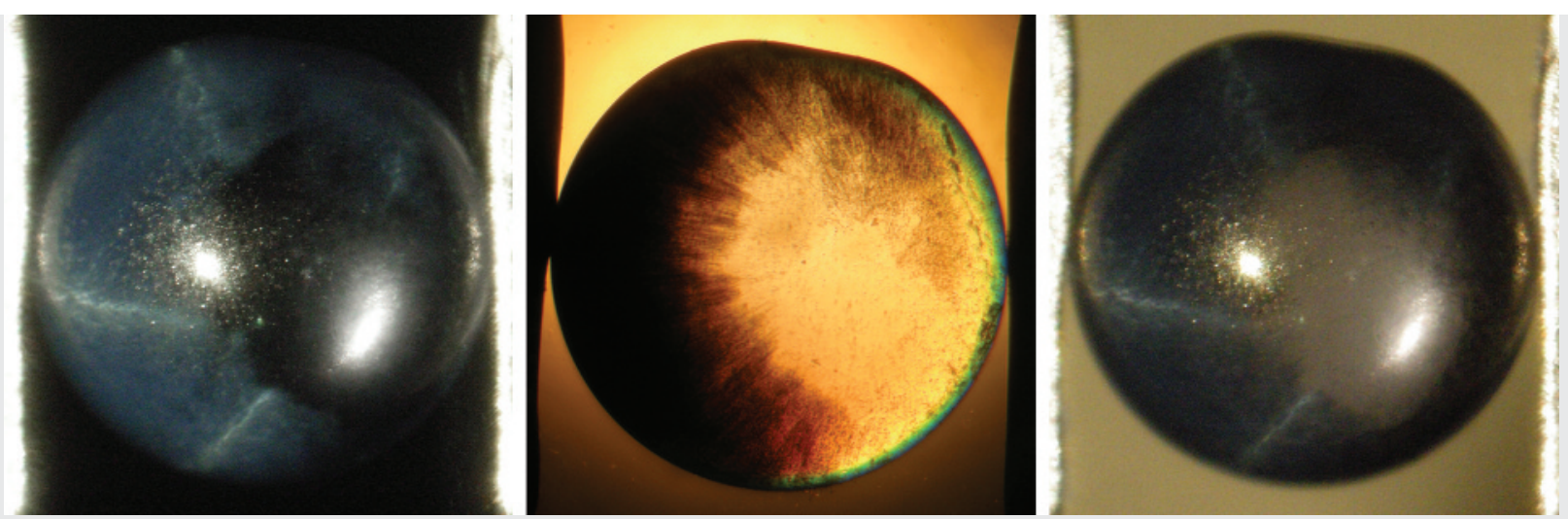

Figure C-1. Linde synthetic blue sapphire with pronounced color zoning and asterism. Left and right: The sample in the same orientation but with a different background. Center: The sample in the same orientation, viewed in immersion. The areas of the cabochon with a high concentration of gas bubbles are blue in daylight and show asterism; those without gas bubbles are colorless and do not show asterism. The sample measures $6.4 \mathrm{~mm}$ in diameter and weighs $1.34 \mathrm{ct}$. Photos by K. Schmetzer; sample courtesy of Gem-A.

under fluctuating thermal conditions. This fluctuation was achieved by alternately increasing and decreasing the rate of oxygen fed to the oxygen-hydrogen flame used for crystal growth in the Verneuil process. This operating protocol caused the formation of alternating convex layers with different titanium distributions (see figure A-2) and led to a homogeneous distribution of the blue coloration as well as the formation of stars with six rays extending equally down the sides of cabochons. This process would probably result in a layered pattern in the concentration of gas bubbles.

Before this technique was applied, most blue synthetic sapphires showed an uneven color distribution and an incomplete star reflected from the surface. Only those samples cut with the dome of the cabochon being formed by the outermost layer of the original corundum boule did not show this undesired zoning. It is assumed that after crystal growth and subsequent annealing to develop rutile precipitates, both samples from the Gem-A collection revealed such an incomplete star associated with an inhomogeneous color distribution. The second sapphire now showing a complete double-star pattern in all differently colored areas most likely was later diffusion treated to improve its visual appearance, especially to produce a complete six-rayed star. Thus, it is proposed that the second sample may be described as a blue synthetic star sapphire with an originally incomplete star that was improved by diffusion treatment. Within that step the second star, reflected and scattered from the base, might also have been formed.

Consequently, the properties of both Gem-A samples would appear to be consistent with the techniques applied by Linde in the early years of production. The appearance of the first sample suggests an absence of post-growth diffusion, while the features of the second sample correspond with what would be expected for one of the early blue Linde sapphires that had been subjected to the diffusion process patented in the 1950s for correction of the incomplete star.

Figure C-2. Linde synthetic blue sapphire with pronounced color zoning and asterism. Left and right: The sample in the same orientation but with a different background. Center: The sample in the same orientation, viewed in immersion. The areas of the cabochon with a high concentration of gas bubbles are intense blue in daylight; those without gas bubbles are lighter blue or colorless. A double-star pattern is observed in all parts of the cabochon. The sample measures $7.0 \times 5.0 \mathrm{~mm}$ and weighs $1.14 \mathrm{ct}$. Photos by K. Schmetzer; sample courtesy of Gem-A.
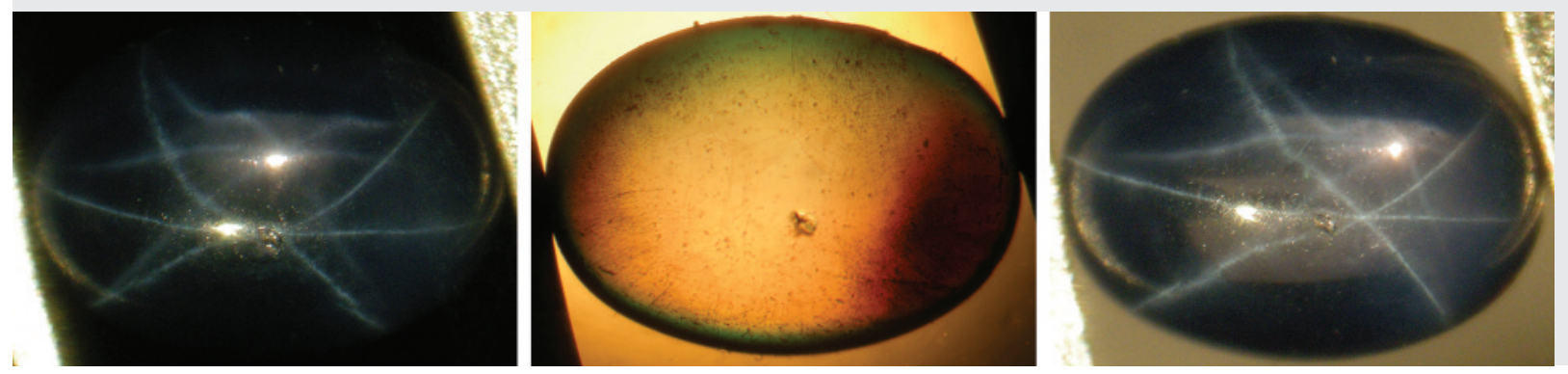


\section{ABOUT THE AUTHORS}

Dr. Schmetzer is an independent researcher living in Petershausen, near Munich, Germany. Mr. Steinbach is a gem merchant and collector residing in Idar-Oberstein, Germany. Prof. Gilg is professor at the Chair of Engineering Geology, Technical University of Munich. Miss Blake is a gemologist residing in Chevy Chase, Maryland.

\section{ACKNOWLEDGMENTS}

This study is based on numerous samples from the collection of one of the authors and on rubies and sapphires kindly submitted from the stock of various companies as well as from different collections: C. Cavey (London); C. Cook and B. Cook (Silk Purse Jewelry, Palmetto, Florida); L. Gleave (Gem-A, London); A. Hodgkinson (Portencross, Scotland); H. Schulz (Wiede's Carbid- werk, Freyung, Germany); and D.L. Snyder (The Brazilian Connection, Benton, Pennsylvania).

Technical information about production and diffusion treatment of Verneuil-grown synthetic corundum was submitted by $\mathrm{H}$. Schulz and C. Schulz (Wiede's Carbidwerk, Freyung, Germany), as well as by Jennifer Stone-Sundberg (Crystal Solutions, Portland, Oregon) and Milan Kokta (Washougal, Washington). H.-J. Bernhardt (Ruhr-University, Bochum, Germany) examined some ruby, sapphire, and quartz samples optically at high magnification. Roald Tagle (Bruker Nano GmbH, Berlin) is acknowledged for help performing the scanning $\mu-X R F$ analyses.

Grinding and repolishing of various samples was performed by Wild and Petsch Company (Kirschweiler, Germany), and by A. Franzmann Company (Hettenrodt, Germany), which are also acknowledged.

\section{REFERENCES}

Alexander A.E. (1946) Genuine and synthetic rubies and sapphires. Journal of Chemical Education, Vol. 23, No. 9, pp. 418-422, 459.

Ancot E., Eppler W.F. (1957a) Verfahren zur Herstellung von synthetischer, Asterismus aufweisender Korunde. DE 1002 300, issued August 14.

Ancot E., Eppler W.F. (1957b) Verfahren zur Herstellung synthetischer Sternkorunde. DE 1007 753, issued October 24.

Applin K.R., Hicks B.D. (1987) Fibers of dumortierite in quartz. American Mineralogist, Vol. 72, No. 1-2, pp. 170-172.

Arem J.E. (1987) Color Encyclopedia of Gemstones, 2nd ed. New York, Van Nostrand Reinhold Company, 248 pp.

Breebaart A.J. (1957) Structure \& inclusions of synthetic starstones. Journal of Gemmology, Vol. 6, No. 2, pp. 72-74.

Burdick J.N., Glenn J.W. Jr. (1949) Synthetic star rubies and star sapphires, and process for producing same. US 2,488,507, issued November 15.

Burdick J.N., Jones R.A. (1953a) Cristaux de corindon synthétique. FR 1.029.418, issued June 2.

Burdick J.N., Jones R.A. (1953b) Improvements in and relating to the manufacture of synthetic corundum containing titanium. GB 697,804, issued September 30

(Burdick J.N., Jones R.A.) The Linde Air Products Company (1953c) Procédé de fabrication d'un corps monocristallin de corindon synthétique. CH 289 320, issued July 1.

Burdick J.N., Jones R.A. (1954a) Synthetic corundum crystals and process for making same. US 2,690,062, issued November 28.

Burdick J.N., Jones R.A. (1954b) Verfahren zur Herstellung von eine Titanverbindung enthaltenden synthetischen Korundkristallen. DE 897 844, issued February 1.

Burdick J.N., Jones R.A. (1956) Verfahren zum Ausscheiden Sternmuster aufweisender Cabochons aus synthetischen Korundeinkristallen. DE 948 403, issued September 20.

Carr R.R., Nisevich S.D. (1973a) Procédé de modification des caratéristiques d'aspect d'un cristal de corindon. FR 2.164.690, issued August 3.

Carr R.R., Nisevich S.D. (1973b) Procédé pour modifier l'aspect de cristaux de corindon et cristaux ainsi obtenus. BE 793.007, issued June 19.
Carr R.R., Nisevich S.D. (1973c) Veränderung des Aussehens von Korundkristallen. DE 2262 104A, issued July 19.

Carr R.R., Nisevich S.D. (1974) Procédé de préparation de cristaux de corindon présentant une coloration sans défaut. CH 554 811, issued October 15.

Carr R.R., Nisevich S.D. (1975a) Altering the appearance of corundum crystals. US 3,897,529, issued July 29.

Carr R.R., Nisevich S.D. (1975b) Treatment of corundum crystals. GB 1408 648, issued October 1.

Carr R.R., Nisevich S.D. (1976a) Altering the appearance of corundum crystals. US 3,950,596, issued April 13.

(Carr R.R., Nisevich S.D.) Union Carbide Corporation (1976b) Verfahren zur Veränderung des Aussehens von Korundkristallen. AT 330 722, issued July 12.

Carr R.R., Nisevich S.D. (1977) Altering the appearance of corundum crystals. US 4,039,726, issued August 2.

Cassedanne J.P., Roditi M. (1991) Crystallized and massive rose quartz deposits in Brazil. Journal of Gemmology, Vol. 22, No. 5, pp. 273-286.

Choudhary G., Vyas M.B. (2009) 'Multiphenomenal' quartz from India. Gems et Jewellery, Vol. 18, No. 1, pp. 10-12.

Crowningshield R. (1965) Pre-1952 synthetic star rubies. Ge G, Vol. 11, No. 11, pp. 331-333.

Crowningshield R., Nassau K. (1981) The heat and diffusion treatment of natural and synthetic sapphires. Journal of Gemmology, Vol. 17, No. 8, pp. 528-541.

Elwell D. (1979) Man-Made Gemstones. Ellis Horwood Ltd., Chichester, $191 \mathrm{pp}$.

Eppler Fr. (1957/1958) Synthetischer Sternsaphir und synthetischer Sternrubin. Zeitschrift der Deutschen Gesellschaft für Edelsteinkunde, No. 22, pp. 4-7.

Eppler W.F. (1958) Notes on asterism in corundum, rose quartz and almandine garnet and chatoyancy in beryl. Journal of Gemmology, Vol. 6, No. 5, pp. 195-212.

Eversole W.G., Burdick J.N. (1954a) Improvement in producing asteriated corundum crystals. GB 712,735, issued July 28.

Eversole W.G., Burdick J.N. (1954b) Procédé de fabrication de cristaux de corindon à structure en étoile. FR 1.067.037, issued June 11. 
Eversole W.G., Burdick J.N. (1954c) Producing asteriated corundum crystals. US 2,690,630, issued October 5.

Eversole W.G., Burdick J.N. (1955a) Verfahren zur Herstellung von strahl- oder sternbildenden (asterisierenden) Korundkristallen. DE 922 584, issued January 20.

(Eversole W.G., Burdick J.N.) Union Carbide and Carbon Corporation (1955b) Procédé de traitement de cristaux de corindon pour les render susceptibles d'astérisation par la chaleur. $\mathrm{CH} 307$ 914, issued July 1.

Fryer C., Crowningshield R., Hurwit K.N., Kane R.E., Eds. (1981) Gem Trade Lab Notes: Star quartz. GÆ G, Vol. 17, No. 4, p. 230. (1982a) Gem Trade Lab Notes: Ruby, synthetic star. $G \uplus G$, Vol. 18, No. 2, pp. 105-106.

(1982b) Gem Trade Lab Notes: Star quartz. GÆG, Vol. 18, No. 4 , p. 231.

(1985) Gem Trade Lab Notes: Quartz, multi- star. $G \uplus G$, Vol. 21, No. 1, pp. 45-46.

Goreva J.S., Ma C., Rossman G.R. (2001) Fibrous nanoinclusions in massive rose quartz: The origin of rose coloration. American Mineralogist, Vol. 86, No. 4, pp. 466-472.

Gübelin E.J., Koivula, J.I. (2008) Photoatlas of Inclusions in Gemstones, Volume 3. Basel, Opinio Publishers, $672 \mathrm{pp}$.

Holmes R.J. (1947) The new "Linde stars." GÆ G, Vol. 5, No. 11, pp. 452-454, 478-479.

He J., Lagerlof K.P.D., Heuer A.H. (2011) Structural evolution of $\mathrm{TiO}_{2}$ precipitates in Ti-doped sapphire $\left(\alpha-\mathrm{Al}_{2} \mathrm{O}_{3}\right)$. Journal of the American Ceramic Society, Vol. 94, No. 4, pp. 1272-1280.

Hughes R.W. (1991) There's a rumble in the jungle: the sapphire face-lift face-off saga. Gemological Digest, Vol. 3, No. 2, pp. 1731. Available at http://www.ruby-sapphire.com/blue_surface_ diffusion.htm

(1997) Ruby « Sapphire. RWH Publishing Boulder, CO, $511 \mathrm{pp}$.

Johnson M.L., Mercer M.E., Fritsch E., Maddison P., Shigley J.E. (1995) "Ti-sapphire": Czochralski-pulled synthetic pink sapphire from Union Carbide. GÆG, Vol. 31, No. 3, pp. 188-195, http://dx.doi.org/10.5741/GEMS.31.3.188.

Keig G.A., Smith J.C., Watts J.M.J. (1972) Asteriated synthetic corundum gem stones and method and apparatus for their production. US 3,655,415, issued April 11.

Keig G.A., Smith J.C., Watts J.M.J. (1973a) Asteriated synthetic corundum gem stones. US 3,725,092, issued April 3.

Keig G.A., Smith J.C., Watts J.M.J. (1973b) Procédé de preparation d'un cristal en corindon astérié synthétique. CH 539 581, issued September 14

Keig G.A., Smith J.C., Watts J.M.J. (1973c) Synthetischer Korund und Verfahren und Vorrichtung zu seiner Herstellung. DE 2208 150A, issued September 6.

(Keig G.A., Smith J.C., Watts J.M.J.) Union Carbide Corporation (1973d) Procédé et dispositif de realization de cristaux de corindon à astérisme. FR 2.172.913, issued October 5.

Keig G.A., Smith J.C., Watts J.M.J. (1974) Synthetic corundum. GB 1377 428, issued December 18.

(Keig G.A., Smith J.C., Watts J.M.J.) Union Carbide Corporation (1976) Synthetischer, monokristalliner Korund. AT 327 863, issued February 25.

Kiefert L. (2003) Gem News International: An unusual star quartz. Ge) G, Vol. 39, No. 3, pp. 234-235.

Killingback H. (2006) Diasterism in rose quartz. Gems \&) JeWellery, Vol. 16, No. 2, p. 64.

(2009) A twelve-ray star rose quartz from Madagascar. Gems et Jewellery, Vol. 18, No. 2, pp. 18-20.

(2011) Diasterism in rose quartz. Midlands Focus, No. 19, pp. $16-25$

Koivula J.I., Kammerling R.C., Eds. (1991) Gem News: Novel synthetic star sapphire. GÆ G, Vol. 27, No. 4, pp. 263-264.

Koivula J.I., Kammerling R.C., Fritsch E., Eds. (1993) Gem News: Unusual double star sapphire. $G \uplus G$, Vol. 29, No. 3, pp. 212-213.
Koivula, J.I., Tannous M. (2001) Gem Trade Lab Notes: Star sapphire with two stars of two different colors. $G \uplus G$, Vol. 37, No. 3, pp. 218-219.

Kokta M.R. (1986) Process for enhancing Ti: $\mathrm{Al}_{2} \mathrm{O}_{3}$ tunable laser crystal fluorescence by annealing. US 4,587,035, issued May 6 .

Kokta M.R. (1987) Process for enhancing Ti: $\mathrm{Al}_{2} \mathrm{O}_{2}$ tunable laser crystal fluorescence by controlling crystal growth atmosphere. US 4,711,696, issued December 8 .

Kokta M.R. (1989) Process for enhancing fluorescence of Ti: $\mathrm{Al}_{2} \mathrm{O}_{3}$ tunable laser crystals. US 4,836,953, issued June 6.

Kokta M.R. (1991) Process for enhancing fluorescence of tunable titanium-doped oxide laser crystals. US 4,988,402, issued January 29.

Kondo D.M. (2007) Lab Notes: Sapphire with a double star. $G \uplus G$, Vol. 43, No. 4, p. 365

Langensiepen R.A., Tressler R.E., Howell P.R. (1983) A preliminary study of precipitation in $\mathrm{Ti}^{4+}$-doped polycrystalline alumina. Journal of Materials Science, Vol. 18, No. 9, pp. 2771-2776.

Liddicoat R.T. Jr. (1963) Early star sapphire. GÆ G, Vol. 11, No. 4, pp. 116-117.

Ma C., Goreva J.S., Rossman G.R. (2002) Fibrous nanoinclusions in massive rose quartz: HRTEM and AEM investigations. American Mineralogist, Vol. 87, No. 2-3, pp. 269-276.

McClure S.F. (1998) Ruby, with a true double star. Ge G, Vol. 34, No. 3, p. 217.

Meyer-Browne G. (1962) Synthetic star stones. The Gemmologist, Vol. 31, No. 376, pp. 201-203,

Moon A.R., Phillips M.R. (1984) An electron microscopy study of exsolved phases in natural black Australian sapphire. Micron and Microscopica Acta, Vol. 15, No. 3, pp. 143-146, http://dx.doi.org/10.1016/0739-6260(84)90044-3.

(1991) Titania precipitation in sapphire containing iron and titanium. Physics and Chemistry of Minerals, Vol. 18, No. 4 pp. 251-258, http://dx.doi.org/10.1007/BF00202577.

Nassau K. (1979) Synthetic gemstone developments in the nineteen seventies. $G \uplus G$, Vol. 16, No. 8, pp. 226-239.

- (1980) Gems Made by Man. Chilton Book Company, Radnor, PA, $364 \mathrm{pp}$

(1981) Heat treating ruby and sapphire: technical aspects. Ge G, Vol. 17, No. 3, pp. 121-131, http://dx.doi.org/10.5741/ GEMS.17.3.121.

Pezzotta F. (2001) Madagascar. A mineral and gemstone paradise. extraLapis English, No. 1, p. 51.

Phillips D.S., Heuer A.H., Mitchell T.E. (1980) Precipitation in star sapphire. I. Identification of the precipitate. Philosophical Magazine A, Vol. 42, No. 3, pp. 385-404.

Pough F.H. (1966) Linde's science re-creates gems in a few hours. Lapidary Journal, Vol. 20, No. 1, pp. 56-64.

Schmetzer K., Bernhardt H.-J., Kiefert L. (2002) Star garnets and star garnet cat's-eyes from Ambatondrazaka, Madagascar. Journal of Gemmology, Vol. 28, No. 1, pp. 13-23.

Schmetzer K., Glas M. (2001) Zwölfstrahliger Sternsaphir aus Bang-kha-cha, Thailand. Lapis, Vol. 26, No. 11, pp. 40-42, 54.

- (2003) Multi-star quartzes from Sri Lanka. Journal of Gemmology, Vol. 28, No. 6, pp. 321-332.

Schmetzer K., Krzemnicki M. (2006) The orientation and symmetry of light spots and asterism in rose quartz spheres from Madagascar. Journal of Gemmology, Vol. 30, No. 3/4, pp. 183191

Schmetzer K., Steinbach M.P (2014) Quartz with sagenitic rutile inclusions from Myanmar. Australian Gemmologist, Vol. 25, No. 5, pp. 175-177.

Schmetzer K., Hainschwang T. (2012) Star ruby. Gems «) Jewellery, Vol. 20, No. 4, pp. 14-17.

Seemann A.K. (1949) American synthetic crystals. GÆG, Vol. 6, No. 5, pp. 151-159.

The story of Linde stars (n.d.) www.thebrazilianconnection. com/Linde_info.html. 
Taylor A.M. (1964) Growth of chrysoberyl crystals and development therein of chatoyancy for cat's-eye gemstones. Technical Memorandum B-390, Status Report, Union Carbide Corporation, Linde Division, 29 pp. (unpublished).

Thai star sapphire (n.d.) http://www.tradeindia.com/fp458250/ Star-Sapphire-Gemstone.html.

Thurm R. (1962) Ein neuer synthetischer Sternsaphir. Zeitschrift der Deutschen Gesellschaft für Edelsteinkunde, No. 39, pp. 27-30.

U.S. develops synthetic sapphire industry (1943) $G \uplus G$, Vol. 4, No. 6, pp. 88-90.

Viti C., Ferrari M. (2006) The nature of Ti-rich inclusions responsible for asterism in Verneuil-grown corundums. European Journal of Mineralogy, Vol. 18, No. 6, pp. 823-834, http://dx.doi.org/10.1127/0935-1221/2006/0018-0823.

von Vultée J. (1955) Über die orientierten Verwachsungen von
Rutil in Quarz. Neues Jahrbuch für Mineralogie Abhandlungen, Vol. 87, No. 3, pp. 389-415.

(1956) Die Verwachsungsgesetze der orientierten Einlagerungen von Rutil in Quarz. Zeitschrift für Kristallographie, Vol. 107, No. 1-2, pp. 1-17.

Woensdregt C.F., Weibel M., Wessicken R. (1980) Star quartz asterism caused by sillimanite. Schweizerische Mineralogische und Petrographische Mitteilungen, Vol. 60, pp. 129-132.

Xiao S.Q., Dahmen U., Heuer A.H. (1997) Phase transformation of $\mathrm{TiO}_{2}$ precipitates in sapphire $\left(\alpha-\mathrm{Al}_{2} \mathrm{O}_{3}\right)$ induced by the loss of coherency. Philosophical Magazine A, Vol. 75, No. 1, pp. 221-238, http://dx.doi.org/10.1080/01418619708210292.

Zolensky M.E., Sylvester P.J., Paces J.B. (1988) Origin and significance of the blue coloration in quartz from Llano rhyolite (llanite), north-central Llano County, Texas. American Mineralogist, Vol. 73, No. 3-4, pp. 313-323.

For online access to all issues of GEMS \& GEMOLOGY from 1934 to the present, visit: 